\title{
NO FREE RIDES: \\ WINNERS AND LOSERS OF THE TTC U-PASS
}

by

\author{
Alex Butler \\ Bachelor of Commerce, University of British Columbia, 2017 \\ A Major Research Paper \\ presented to Ryerson University \\ in partial fulfillment of the requirements for the degree of \\ Master of Planning \\ in \\ Urban Development \\ Toronto, Ontario, Canada, 2019
}

(C) Alex Butler 2019 


\section{$\underline{\text { Author's Declaration for Electronic Submission of a MRP }}$}

I hereby declare that I am the sole author of this MRP. This is a true copy of the MRP, including any required final revisions.

I authorize Ryerson University to lend this paper to other institutions or individuals for the purpose of scholarly research.

I further authorize Ryerson University to reproduce this MRP by photocopying or by other means, in total or in part, at the request of other institutions or individuals for the purpose of scholarly research.

I understand that my MRP may be made electronically available to the public. 


\title{
NO FREE RIDES: \\ WINNERS AND LOSERS OF THE TTC U-PASS
}

\author{
(C) Alex Butler, 2019 \\ Master of Planning \\ in \\ Urban Development \\ Ryerson University
}

\begin{abstract}
$\underline{\text { Abstract }}$
This paper explores the financial gains and losses for students from the U-Pass scheduled to be implemented by the Toronto Transit Commission (TTC) at universities in Toronto, Ontario in fall 2019. The U-Pass offers students unlimited travel on the TTC for $\$ 70$ per month, but students are unable to opt-out. Toronto already has high existing student transit ridership and fares that are not integrated across municipal boundaries, setting a context in which U-Pass impacts different students in different ways. This study uses data from the 2015 StudentMoveTO survey to determine the financial losses and gains from students across different campuses, commute modes, and geographies. Students that benefit live within the City of Toronto and use TTC to get to school, while those expected to experience welfare losses either live outside of Toronto or live close enough to their campus to walk or bike to school.
\end{abstract}

1. An article about U-Pass in Toronto, used the key words: transit fares, student travel, equity 


\section{$\underline{\text { Acknowledgements }}$}

First, I want to thank my supervisor, Dr. Matthias Sweet, for his guidance over the course of this project. The dozens of meetings, help interpreting statistical results, and feedback on multiple drafts was greatly appreciated. Thank you for making yourself available and encouraging me when I thought I was in over my head. I truly could not have done this without your help and support.

I also want to thank my second reader, Graham Procter, for his time and thoughtful comments throughout this project. I greatly appreciate you using your leisure time to help me finish a paper I am proud of.

Lastly, I need to acknowledge my classmates from whom I learned so much over the past two years. Plenty of discussions at the bar come to mind that have taught me to think about planning issues with a critical eye. 


\section{Table of Contents}

Author's Declaration for Electronic Submission of a MRP ....................................................... ii

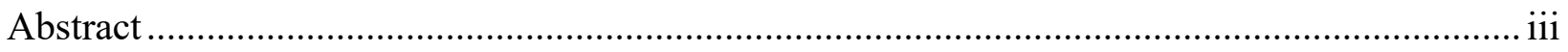

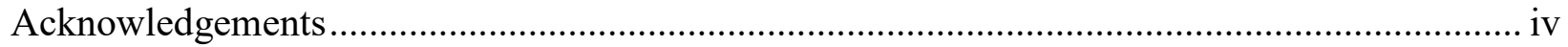

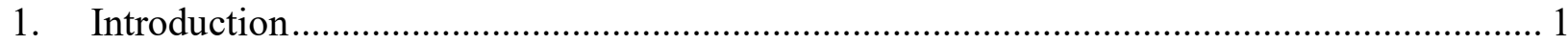

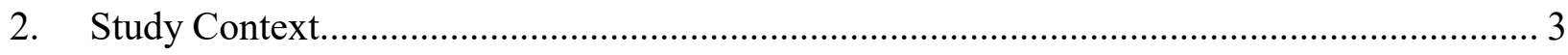

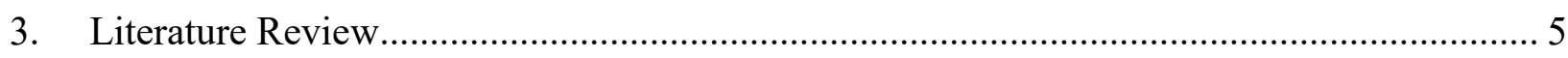

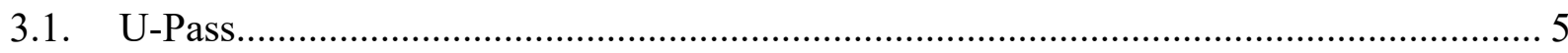

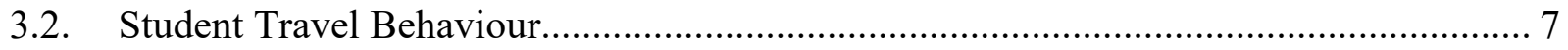

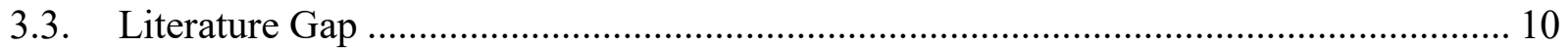

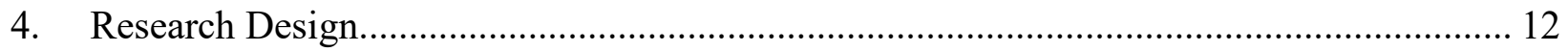

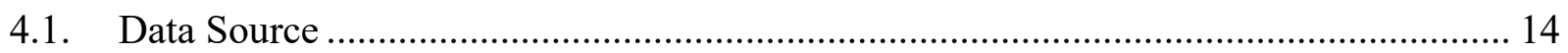

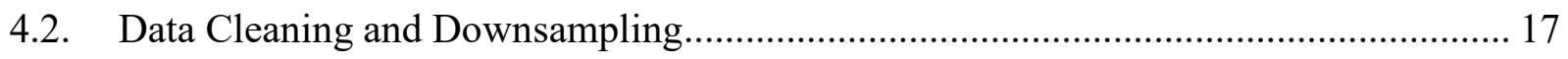

4.3. Trip Categorization ............................................................................................ 19

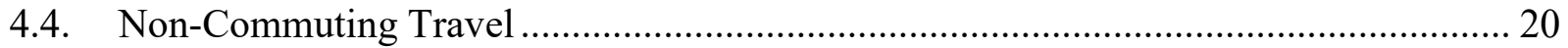

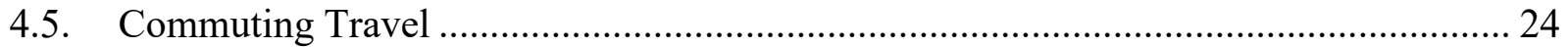

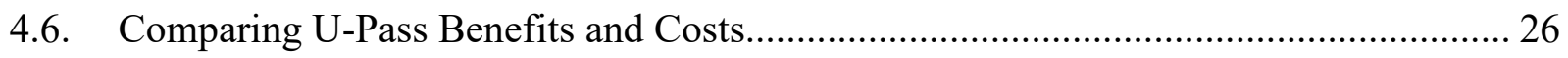

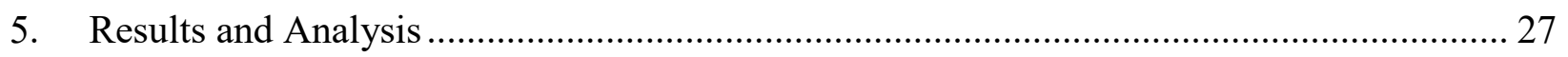

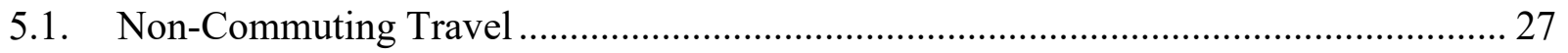

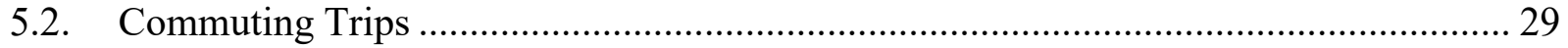

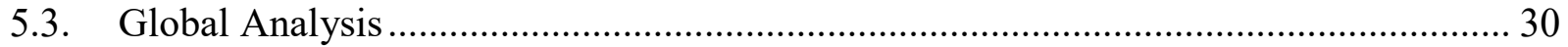

5.4. Sub-Market Analysis.......................................................................................... 32

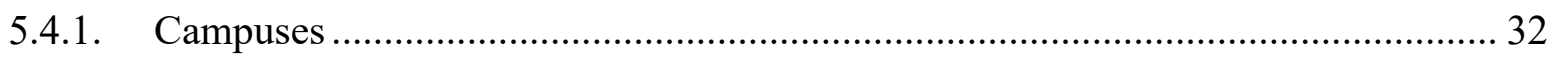

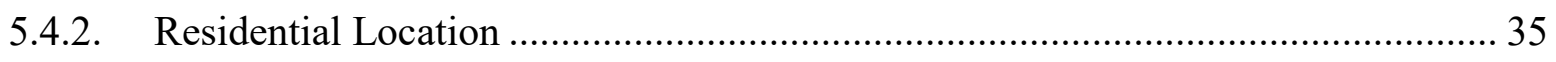

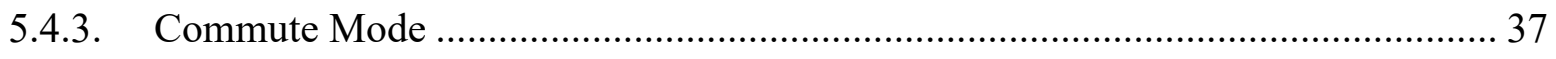

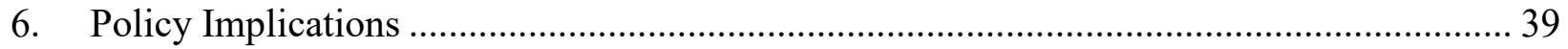

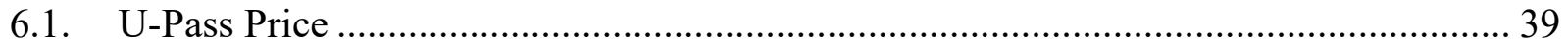

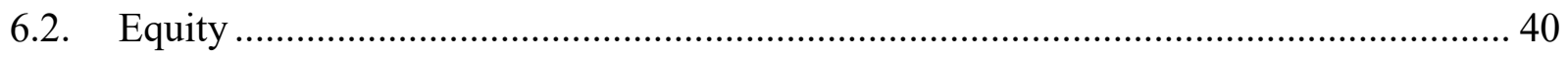

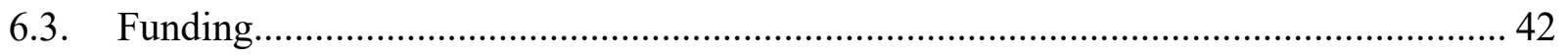

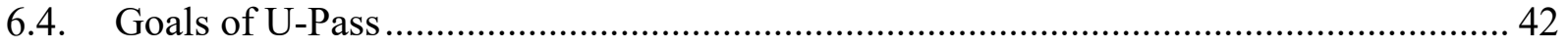

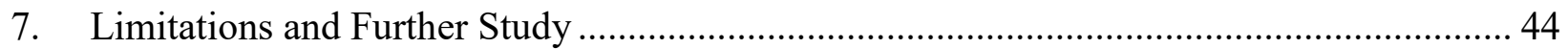

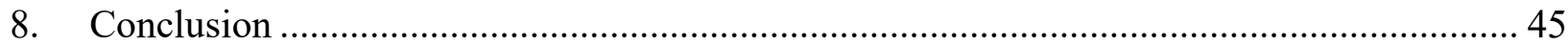

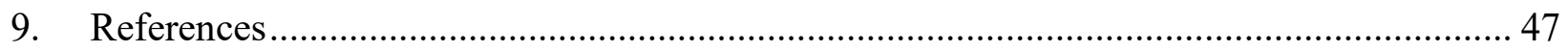




\section{List of Tables}

Table 1: Literature Review of Significant Factors Influencing Student Travel Behaviour......... 10

Table 2: Student Fall Commute Mode to School........................................................................ 16

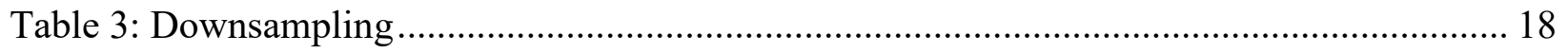

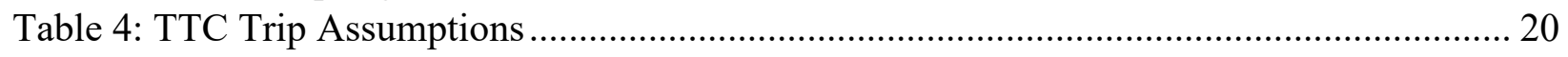

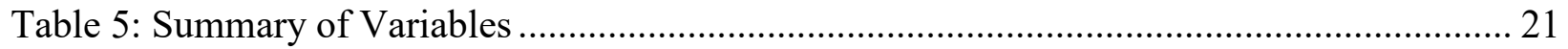

Table 6: Predictors of Negative Binomial Model ................................................................. 28

Table 7: Frequency of TTC Commute to Campus.................................................................. 29

\section{List of Figures}

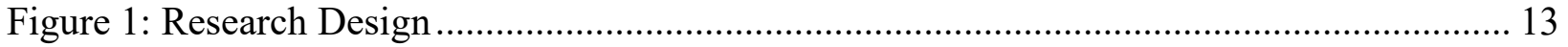

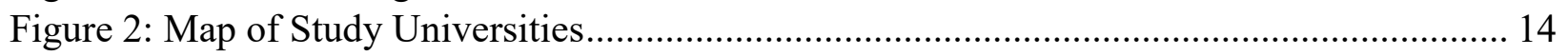

Figure 3: Student Fall Commute Mode to School ................................................................ 15

Figure 4: Cheaper Transit Fares Motivate Change in Commute Mode by Current Mode ........... 16

Figure 5: Transit Commuters' Top Method to Improve Commute ......................................... 17

Figure 6: Number of Estimated Non-Commuting TTC Trips per Student per Term ................. 29

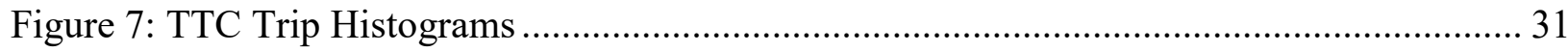

Figure 8: Estimated TTC Trips Categorized by Usage Level................................................ 32

Figure 9: Estimated TTC Trips Categorized by Usage Level by Campus ................................ 33

Figure 10: Mean Savings or Loss from U-Pass by Campus Attended (Four Month Period) ....... 34

Figure 11: TTC Trips Categorized by Residential Location ................................................ 35

Figure 12: Savings or Losses for Toronto and Non-Toronto Residents .................................. 36

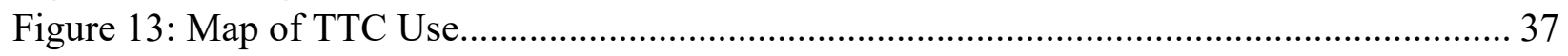

Figure 14: TTC Trips by Regular Commute Mode to School .................................................... 38

Figure 15: Average Benefit or Loss by Regular Commute Mode to School.............................. 38

Figure 16: Monthly TTC Spending by Campus ................................................................ 40 


\section{Introduction}

Students make up a significant portion of the traveling public (Khattak et al., 2011) and are therefore a large source of ridership and revenue for transit operators. In the Greater Toronto and Hamilton Area in Ontario, Canada, students make up 18\% of all trips and $34 \%$ of transit trips, making them a huge source of ridership and revenue for transit operators. ${ }^{1}$ The travel habits and preferences that students develop through their time at school also stays with them beyond graduation (Busch-Geertsema and Lanzendorf, 2017).

One of the policy solutions to encourage public transit use among students is a U-Pass program. U-Passes offer unlimited transit use for college and university students and are often funded through fees collected from all students, regardless of actual transit use. They are a popular and effective solution to encourage and facilitate the use of public transit throughout the United States and Canada, however their funding has broader implications. For one, U-Passes redistribute resources, leading to relative losses and improvements in welfare among different groups. Students that are heavier users of transit stand to benefit, while those that travel using active modes or driving stand to lose. Additionally, students living outside of the service area are not able to take advantage of the service they are obligated to pay for. U-Passes also lead to a redistribution of resources between the student body and the service provider. While a low-cost U-Pass program with high ridership may yield significant benefits for students, a high-cost program with low ridership may simply offer a large and stable revenue stream to transit operators at the expense of students. This paper focuses on each of these elements by evaluating the recently approved Toronto Transit Commission (TTC) U-Pass program in Toronto, Ontario, which will be implemented in fall 2019. The fragmented nature of transit fares in the region

\footnotetext{
${ }^{1}$ Calculated from data from the 2016 Transportation Tomorrow Survey 
among different service providers, as well as high existing ridership from students make the Greater Toronto Area a unique context in which to study U-Pass, necessitating this research. By modeling and summarizing responses from a survey of students' travel behaviour called StudentMoveTO, this paper asks what students would benefit and which would be disadvantaged by the U-Pass. 


\section{Study Context}

In March 2018, the TTC board unanimously approved a program that would allow postsecondary students unlimited travel for $\$ 70$ per month, a discount from the current price of $\$ 116.75$ for an unlimited post-secondary transit pass (Baig, 2018). The pass does not include an option to opt-out and the fee is added to students' tuition. To be implemented, students at each post-secondary institution must vote to accept or reject the proposal. Students at the University of Toronto St. George campus already voted against the U-Pass with $66 \%$ of voters opposed (Spurr, 2018). At Ryerson University, the proposal passed with $63 \%$ of students in favour and will be in force starting in September 2019 (Ryerson University, 2018).

U-Pass programs exist in jurisdictions across Canada including Vancouver, Ottawa, Calgary and others. In the Greater Golden Horseshoe (the geographic area surrounding Toronto), Waterloo, Hamilton, Mississauga, and Durham Region have U-Pass programs that serve a total of 14 institutions at a cost for students between $\$ 15.22$ and $\$ 25.25$ per month that is bundled into student fees (TTC, 2017), significantly less than the TTC proposal of $\$ 70$ per month. The price point of $\$ 70$ was proposed in order to have the program be revenue and cost neutral and make up for the estimated $\$ 61.7$ million in annual revenue currently collected from students as well as the additional service hours necessary to service a $15 \%$ increase in trips (TTC, 2018).

The Greater Toronto Area presents a unique and challenging context in which to implement U-Pass due to a lack of fare integration across the region and high existing transit ridership from students. In the Greater Toronto Area, there are eleven different transit agencies across the region that charge separate fares. Students that live outside the City of Toronto need to use other local transit agencies or regional transit provided by GO Transit to get to school or make other trips. Fares on these agencies are often more expensive than TTC. Therefore, 
students in the outer suburbs would need to pay for both a TTC pass they will get little use from, as well as fares for the agency they use regularly. The U-Pass would also charge students who currently use active transportation for their daily needs. The initiative would be expected to benefit students that make a trip using TTC at least 94 times per four-month term $(\$ 280$ for the total term cost divided by $\$ 3$ per trip). Students taking fewer than 94 trips per term would be expected to pay more in upfront fees relative to travel-related benefits from the program. This paper uses empirical data to estimate which students would benefit financially and which would not. Note that there may be other benefits to changes in fare policy such as decreasing congestion, decreasing greenhouse gas emissions, or enabling more travel, however this analysis focused on the direct financial implications for students. Potential second-order or induced effects of this proposed fare structure are discussed, but not the core focus of this study. 


\section{Literature Review}

Understanding the potential travel and distributive impacts of U-Pass programs hinges on two important bodies of research. The first is about the implementation and impacts of U-Pass programs across the United States and Canada. The second is comprised of studies about student travel behaviour and informs the modelling approach used to explore student travel behaviour in this paper.

\subsection{U-Pass}

U-Pass programs are often implemented to increase ridership or achieve other transportation demand management objectives (Brown et al., 2001). They are frequently supported by students because they offer cost savings and environmental benefits (Myers et al., 2006). The motivations and implementation of U-Pass programs relate to increasing ridership, decreasing parking demand, and saving money for students.

As a monthly transit pass for students, U-Passes have significant implications for expected transit use rates. Among the general population in Toronto, monthly transit pass holders take four times as many trips as non-transit pass holders (Badoe and Yendeti, 2007). The decision to own a pass is influenced by socioeconomic characteristics, workplace location, access to free parking, and accessibility to transit. However, the decision to own a transit pass is an endogenous variable in the number of transit trips taken by an individual. This means that individuals make simultaneous decisions on both the number of transit trips they expect to take and the expected value from purchasing a transit pass. In fact, students are already more likely to own a transit pass than the general population (Badoe and Yendeti, 2007).

Miller (2001) noted that U-Pass programs were in place as early as the late 1960s, but expanded significantly during the 1990s. This increase in popularity was due to increased 
funding for transit, while transit systems were expanding and offering higher quality service. Furthermore, there was a recognition that these programs contribute to the objectives of reducing parking demand, increasing access to housing and employment, and reducing congestion (Miller, 2001).

Brown et al. (2001) in a survey of 35 universities with U-Pass programs, found that campus officials' top reasons for offering U-Pass were parking demand reduction, increasing students' access to housing and employment, recruitment, reducing costs for students, and concerns for equity. Among transit officials, their top reasons were increased ridership, guaranteed revenues, and improvements to overall transit service.

Both the benefits and rationales of student U-Pass programs vary. Students at Western Washington University in Bellingham, Washington were asked if they favoured a U-Pass. Of those that did, their top reasons were added night service, money saved, and positive environmental impacts (Myers et al., 2006).

Several case studies of U-Pass programs have shown that they increase ridership (Boyd, 2003; Brown, 2003 Meyer et al., 1998; Meyer et al., 2006). Fare elasticities of transit demand across campuses in the United States range from -0.26 to -0.50 (Brown, 2001), implying that free transit would increase transit demand by $26-50 \%$. While U-Passes are expected to increase ridership, they are often introduced at the same time as transit improvements or transportation demand management programs aimed at decreasing vehicle usage (Williams 1993; Brown, 2001). Brown et al. (2001) speculate that increased ridership after U-Pass implementation is not only due to the U-Pass itself. Rather, ridership increases may be due to several factors including reduced fares, improved service, reduced automobile ownership, residential relocation, and improved mental maps of transit facilities. 
Regarding funding method, Brown et al.'s survey of 35 universities in the United States found that 25 of the 35 U-Pass programs were funded at least in part by student fees at a cost between $\$ 5$ and $\$ 90$ USD per month (2001). Other funding sources include parking revenues, general funds from universities, and government contributions (Miller, 2001). The TTC U-Pass will be funded solely by student fees.

Beyond funding, a U-Pass program also requires student support. Myers et al. (2006) found that students at Western Washington University in Bellingham had a much higher support for a U-Pass if they lived closer to campus. Of those that indicated they would vote against UPass, the most popular reasons were that the price is too high, it did not meet the student's needs, and that they prefer an optional fee (Myers, 2006). This is significant because a student referendum is usually required to implement a U-Pass through student fees (Miller, 2001) and the TTC U-Pass proposal is no exception.

\subsection{Student Travel Behaviour}

Student travel behaviour can be predicted with the different factors explored in this section. Studies of environmental factors influencing student travel behaviour have shown differences in urban and suburban campuses, as well as the impacts of residential density and sidewalk density (Khattak et al., 2011; Rodriguez and Joo, 2004; Whalen et al., 2013). In Hamilton, Ontario, students at McMaster University that lived in areas with higher road density and lower sidewalk density were more likely to drive or use transit than use active transportation (Whalen et al., 2018). At the University of North Carolina Chapel Hill, using data from 1997, Rodriguez and Joo (2004) noted that sidewalk and residential density were positively correlated with a propensity for walking, but negatively correlated with a propensity for transit due to these environments being more pedestrian friendly. These findings follow work that identifies density, land-use diversity, and design as important environmental influencers of non-auto transportation 
(Cervero and Kockelman, 1997). Khattak et al. (2011) discovered that the travel behaviour of students at urban and suburban campuses differ and that the students at urban schools had a higher trip rate. One study in Virginia and another in Halifax found that students that live on campus are less likely to drive and use active transportation more often (Daisy et al., 2018; Khattak et al., 2011).

Residential location including distance to transit and distance from campus also impact students' travel decisions. Distance from residence to a transit stop is a significant factor in predicting transit use (Collins and Chambers, 2005; Zhou, 2014; Zhou, 2016). Zhou (2014) also found that students are more likely to share residences to have cheaper rent and proximity to bus service.

Multiple studies have identified cost as a significant factor impacting mode choice (Akar et al., 2012; Hasnine et al, 2018; Zhou, 2014). Hasnine et al. (2018) estimated that in Toronto, a $50 \%$ reduction in transit fares would increase transit mode share from students by $2 \%$ and that incentives to purchase transit passes would encourage local transit. In a study in Los Angeles, Zhou (2014) found that a subsidized transit pass would not only increase transit use, but also increase the use of active modes of transportation. Changes in the cost of travel (in time or price) lead to near-term and long-term mode shifts (Cervero, 2002). This is important for understanding the impacts of changes in fare policy.

Household factors like the number of dependent children also impact travel behaviour. For example, students with dependent children were more likely to drive and less likely to bike (Hasnine et al., 2018; Delmelle and Delmelle, 2012).

Students are generally more reliant on non-automotive transportation (Khattak et al., 2011; Akar et al., 2012). However, while students are a distinct group that travel differently from 
the general population (Khattak et al., 2011), their behaviour varies based on factors like age, their status as an undergraduate or graduate student, and whether they are full or part-time students. Some studies have considered age in student travel behaviour models and generally found that age is negatively correlated with transit use (Daisy et al., 2018; Hasnine et al., 2018; Zhou, 2012; Zhou, 2016). Undergraduate students have shorter commutes and are more likely to use active transportation (Zhou, 2014; Zhou, 2016). Male students were also more likely to use active transportation (Zhou, 2016). Other research has found that students that do not drive are more likely to use multiple modes of transportation (Lavery et al., 2013; Zhou, 2012). Students that live on campus are also more likely to use sustainable modes of transportation (Khattak et al., 2011).

While not a complete list of the explanations of travel behaviour, Table 1 shows the variables relevant to this study that were used in other studies on student travel behaviour in North America. These variables are used in this study's research design. 
Table 1: Literature Review of Significant Factors Influencing Student Travel Behaviour

\begin{tabular}{|c|c|c|c|c|c|c|c|c|c|c|c|c|c|c|c|c|}
\hline Variable & $\begin{array}{l}m \\
\stackrel{n}{0} \\
\frac{N}{\pi} \\
+ \\
\frac{0}{\sigma} \\
\frac{\pi}{\alpha}\end{array}$ & 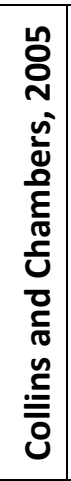 & 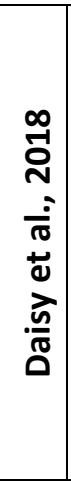 & 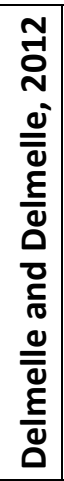 & 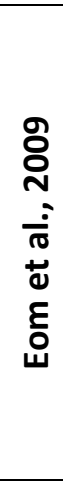 & 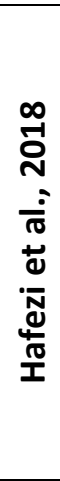 & 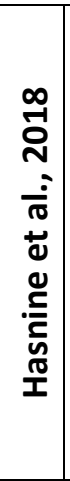 & 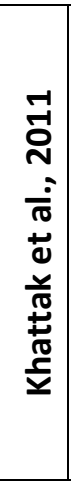 & 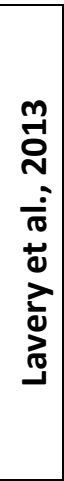 & 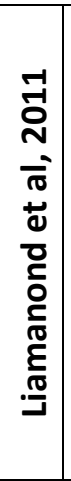 & 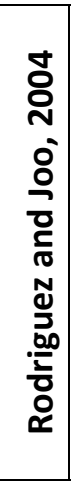 & 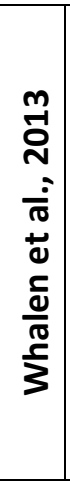 & 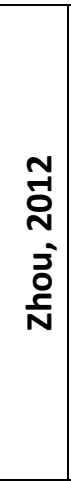 & $\begin{array}{l}\stackrel{d}{2} \\
\stackrel{N}{N} \\
\dot{3} \\
\frac{0}{N}\end{array}$ & 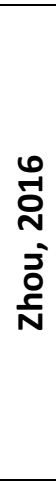 & 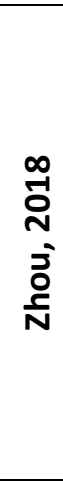 \\
\hline Age & & & $x$ & & & & $x$ & & & & & & $x$ & & $x$ & \\
\hline Area Household Income & & & & & & & & & $x$ & & & & & & & \\
\hline Dependent Children & & & & $\mathrm{x}$ & & & $\mathrm{x}$ & & & & & & & & & \\
\hline Distance from Campus & & & $X$ & & & & $\mathrm{X}$ & & $x$ & & & & & & $x$ & $x$ \\
\hline Distance to Transit & & $\mathrm{X}$ & & & & & & & & & & & & $x$ & $x$ & \\
\hline Gender & $x$ & & & $x$ & & & $\mathrm{x}$ & & & & $x$ & & & $x$ & & \\
\hline Home Ownership & & & $X$ & & & & & & & & & & & & & \\
\hline Living Situation & & & & $x$ & & & & & & & & $x$ & & & & \\
\hline On-Campus Residence & & & & & $x$ & & & $\mathrm{X}$ & & & & & & & & \\
\hline Population Density & & & & & & & & & $x$ & & $\mathrm{X}$ & $x$ & & & & \\
\hline Sidewalk Availability & & & & & & & $x$ & & & & $\mathrm{X}$ & $x$ & & & & \\
\hline Street Density & & & & & & & & & & & & $x$ & & & & \\
\hline Undergrad vs. Grad Status & $x$ & & & $x$ & & $X$ & & & & & & & & $\mathrm{X}$ & & \\
\hline Vehicles Available & & & & & & & $x$ & & $x$ & $x$ & $x$ & & & & & \\
\hline
\end{tabular}

\subsection{Literature Gap}

Existing research includes many case studies of U-Pass programs in the United States and discusses impacts of ridership and mode split. Furthermore, it identifies the benefits, detriments, and challenges of creating and maintaining a U-Pass program. However, it does not discuss Canadian case studies and context, despite the prevalence of these programs across Canada. Furthermore, no academic study had yet analyzed the TTC's U-Pass program. This study will fill this gap by analyzing the utility of the TTC U-Pass in depth. The research design uses the variables found in Section 3.2 to estimate the number of TTC trips taken by students in the Greater Toronto Area. 
Toronto is a unique context in which to study U-Pass. Many of the studies examining the benefits and impacts of U-Pass programs were in the context of low transit mode share. Toronto is unique in that it has a high existing transit ridership among students, bringing into question what the goals of the program are. Furthermore, few studies explore the challenges of planning a U-Pass program for regions like the Greater Toronto Area where there are multiple transit agencies, of which only one (TTC) is included in the pass. While two studies analyzed the BruinGO U-Pass at UCLA where multiple transit agencies existed (Boyd, 2003; Brown, 2003), neither discussed the lack of fare integration as Santa Monica Bus Lines was included in the BruinGO pass and accounted for the vast majority of transit to campus. Furthermore, trips were paid for from university funds, not directly through student fees, making it less contentious. This study highlights the fragmented nature of transit fares and unequal distribution of benefits for the TTC U-Pass in the Greater Toronto Area. 


\section{Research Design}

This study aims to discover who benefits and who is burdened financially from the TTC U-Pass. To make use of the $\$ 70$ monthly fee, students would need to take at least 94 trips in one four-month school term. This study uses survey data to explore the redistributive impacts based on models and analyses of observed student travel behavior. The primary source of data for this paper is the 2015 StudentMoveTO survey, which includes demographic and attitudinal information on each respondent, as well as a trip diary. The goal of the following methodology was to estimate the number of TTC trips taken in a four-month school term by each student surveyed.

The research design illustrated in Figure 1 includes the following steps:

1. The dataset was downsampled, so the sample would better represent the student population at Toronto post-secondary institutions.

2. The number of non-commuting TTC trips taken by each student was estimated using a negative binomial model.

3. The number of school commuting TTC trips taken by each student was estimated using responses from StudentMoveTO.

4. The estimated commuting and non-commuting trips were summed to estimate the total number of TTC trips taken by each student in a four-month term.

5. Transit trips were re-estimated for different fare policy scenarios to reflect changes in fare policy that have occurred since the survey was taken (see Sections 4.4 and 4.5).

6. An analysis of which students benefit and which do not based on the number of TTC trips taken by each student was conducted. 
Figure 1: Research Design

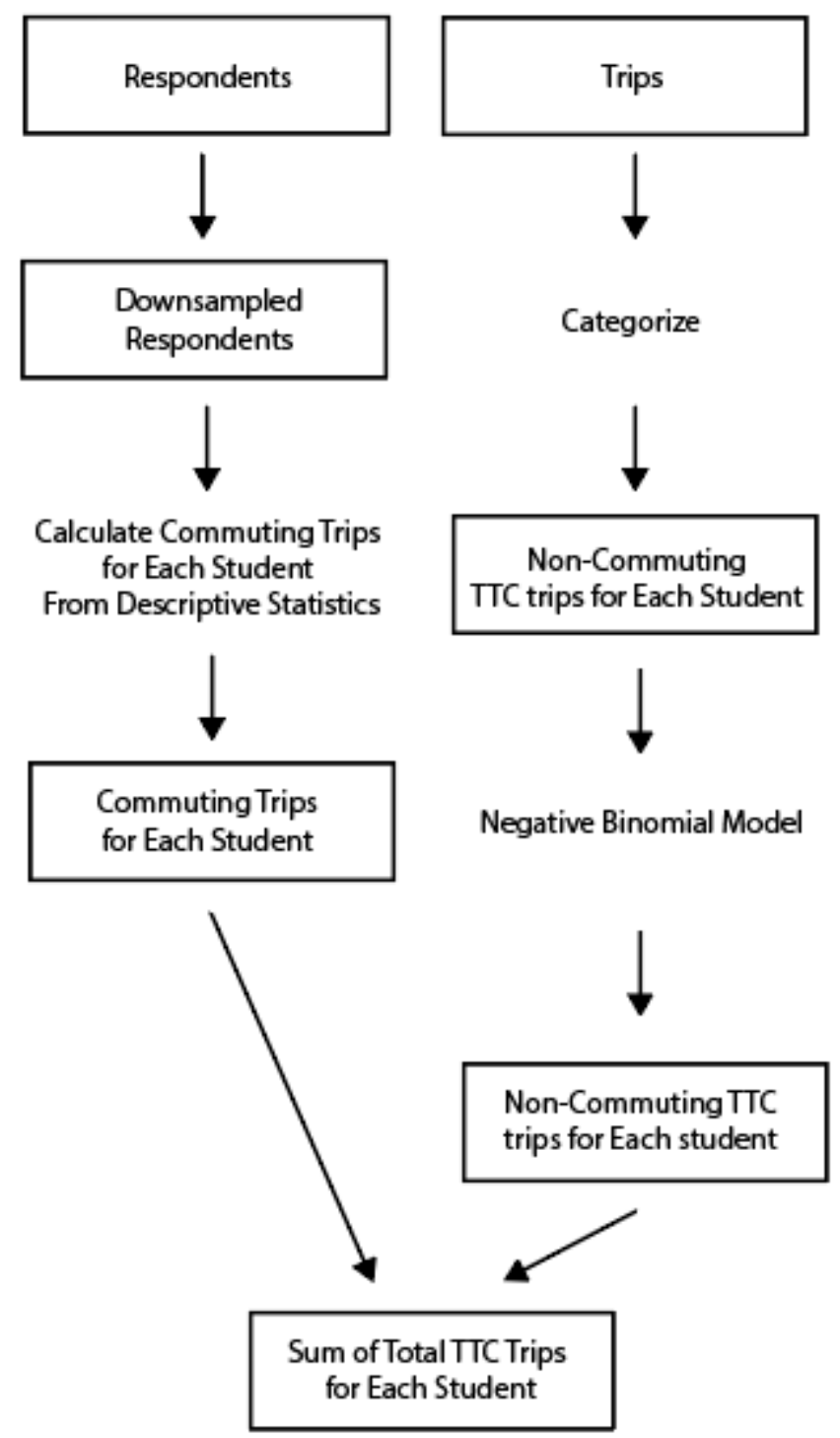

Commuting and non-commuting trips are estimated separately in this study because commuting trips are habitual and most students reported either 0 or 2 trips on the day of their trip diary depending on whether or not they commuted to campus. Given that the survey question reflected "typical" commuting behavior, weekly and term trip rates were estimated directly using survey responses. However, because each student's discretionary transit use was only available for a single day in the travel diary, weekly trip rates for discretionary travel (and subsequently 
term trip rates) were estimated using a negative binomial model using guidance from the existing literature and the available data.

\subsection{Data Source}

StudentMoveTO ${ }^{2}$ is a dataset that includes over 15,000 survey responses of students' travel behaviour and attitudes from fall 2015 in the Greater Toronto Area. Students from Ryerson University, the University of Toronto (St. George, Mississauga, and Scarborough campuses), the Ontario College of Art and Design (OCAD), and York University (Glendon and Keele campuses) were randomly sampled. For the purposes of this study, responses from the University of Toronto Mississauga campus were excluded as that campus falls outside of the City of Toronto and would not be eligible for the TTC U-Pass. In addition to demographic and attitudinal questions, it includes a one-day travel diary for each student that includes each trips' destination, origin, mode, and purpose.

Figure 2: Map of Study Universities ${ }^{3}$

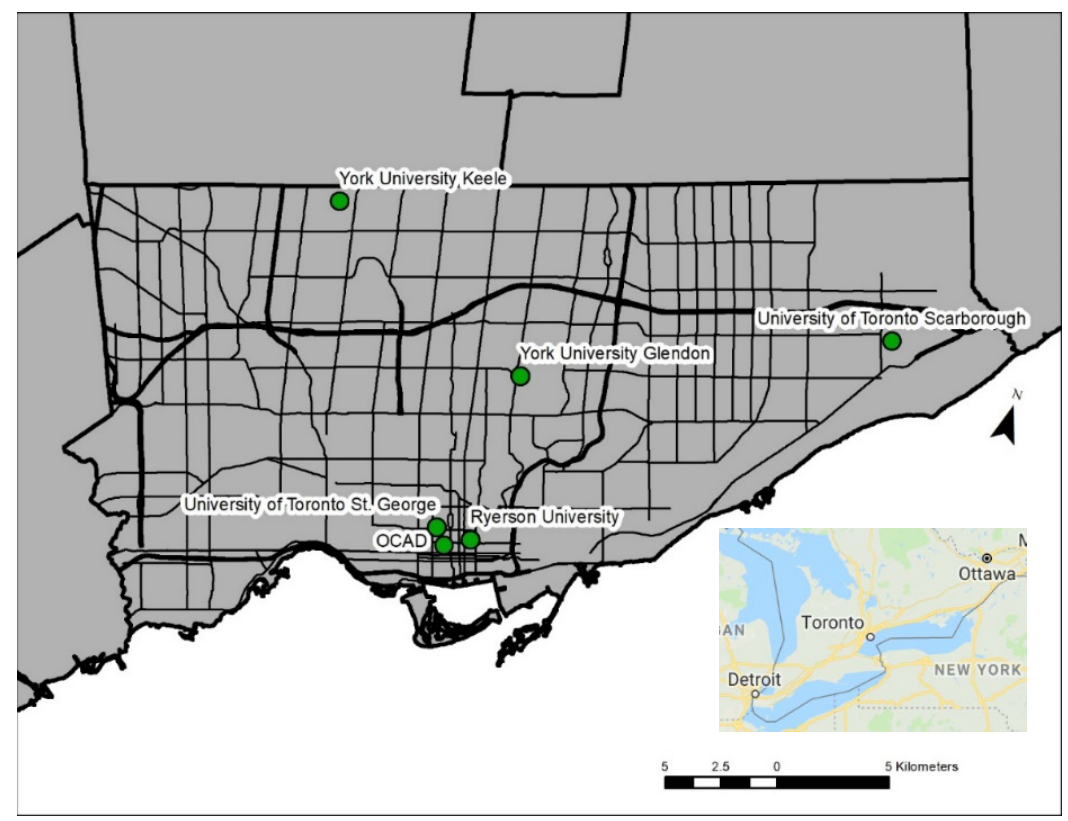

\footnotetext{
${ }^{2}$ The StudentMoveTO data is available by request at studentmoveto.ca. Summary findings are freely available on the website.

${ }^{3}$ Inset source: Google Maps; Roads, boundaries, and campus locations from City of Toronto Open Data.
} 
Descriptive statistics of the dataset show several insights into the travel behaviour of students. First of all, students in the Greater Toronto Area are heavy users of transit and active transportation for commuting. Half of respondents reported using local transit to get to school and 38\% already possess at least one transit pass. While this could include some students using other transit agencies such as York Region Transit, most of these commuters are likely using TTC. A limitation of the dataset is that different local transit agencies in the region were not differentiated in the responses.

Notably, $14 \%$ of students use regional transit to commute to school on GO Transit. GO Transit is a regional transit operator that runs express trains and buses over long distances. At Ryerson University, $23 \%$ of students use GO Transit to commute to school. This is a significant commuting mode for students living outside of the City of Toronto. GO Transit fares range in price depending on distance and frequency of travel, however they generally start at $\$ 5.30$ for each one-way trip and are higher depending on distance. Travel on GO Transit would not be included in the $\$ 70$ TTC U-Pass as it has been proposed. Only $8 \%$ of students attending Toronto universities reported travelling to school as a driver or passenger.

Figure 3: Student Fall Commute Mode to School

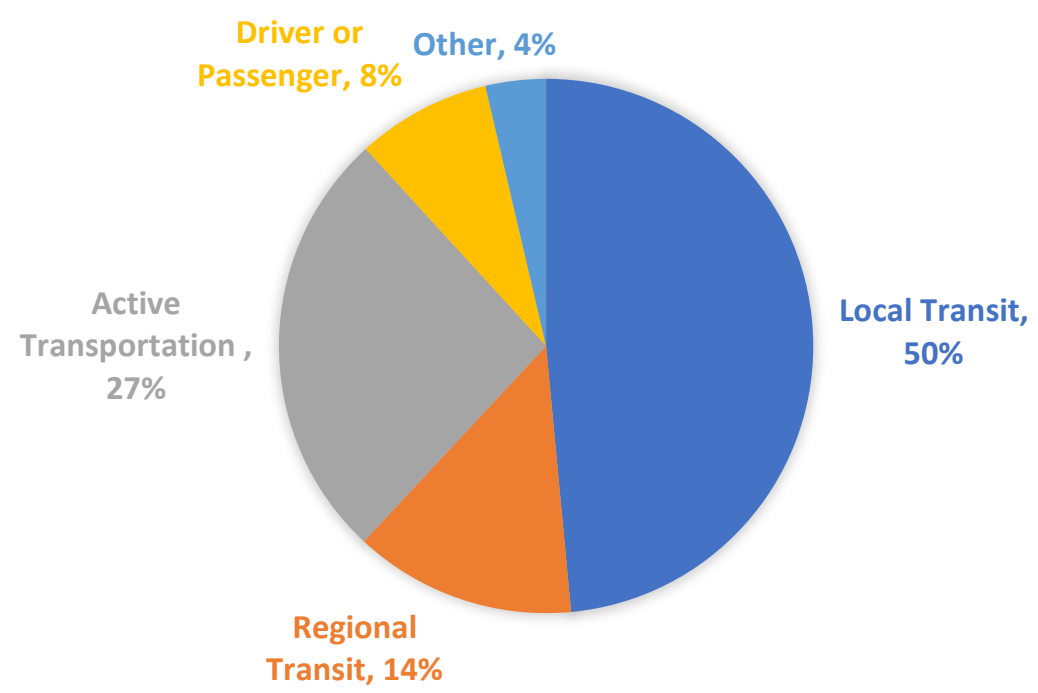


Table 2: Student Fall Commute Mode to School

\begin{tabular}{|l|c|c|c|c|c|}
\hline & $\begin{array}{l}\text { Local } \\
\text { Transit }\end{array}$ & $\begin{array}{l}\text { Regional } \\
\text { Transit }\end{array}$ & $\begin{array}{l}\text { Active } \\
\text { Transportation }\end{array}$ & $\begin{array}{l}\text { Driver or } \\
\text { Passenger }\end{array}$ & Other \\
\hline $\begin{array}{l}\text { University of Toronto } \\
\text { (St. George) }\end{array}$ & $43 \%$ & $10 \%$ & $42 \%$ & $4 \%$ & $2 \%$ \\
\hline $\begin{array}{l}\text { University of Toronto } \\
\text { (Scarborough) }\end{array}$ & $59 \%$ & $5 \%$ & $14 \%$ & $21 \%$ & $11 \%$ \\
\hline York University (Keele) & $55 \%$ & $16 \%$ & $12 \%$ & $16 \%$ & $5 \%$ \\
\hline $\begin{array}{l}\text { York University } \\
\text { (Glendon) }\end{array}$ & $58 \%$ & $10 \%$ & $13 \%$ & $15 \%$ & $9 \%$ \\
\hline Ryerson University & $54 \%$ & $23 \%$ & $19 \%$ & $4 \%$ & $2 \%$ \\
\hline OCAD & $47 \%$ & $19 \%$ & $30 \%$ & $3 \%$ & $1 \%$ \\
\hline Grand Total & $\mathbf{5 0 \%}$ & $\mathbf{1 4 \%}$ & $\mathbf{2 7 \%}$ & $\mathbf{8 \%}$ & $\mathbf{4 \%}$ \\
\hline
\end{tabular}

U-Pass is often touted as a way to encourage use of public transit. Of students that currently do not commute using public transit, $30 \%$ said that decreasing the cost of public transit would motivate them to change their mode of commuting to school. However, of those $30 \%$, $74 \%$ were active transportation commuters. Of solo auto commuters, $26 \%$ indicated an interest in changing commute mode should transit fares be cheaper, however these students make up a small portion of the total sample.

Figure 4: Cheaper Transit Fares Motivate Change in Commute Mode by Current Mode

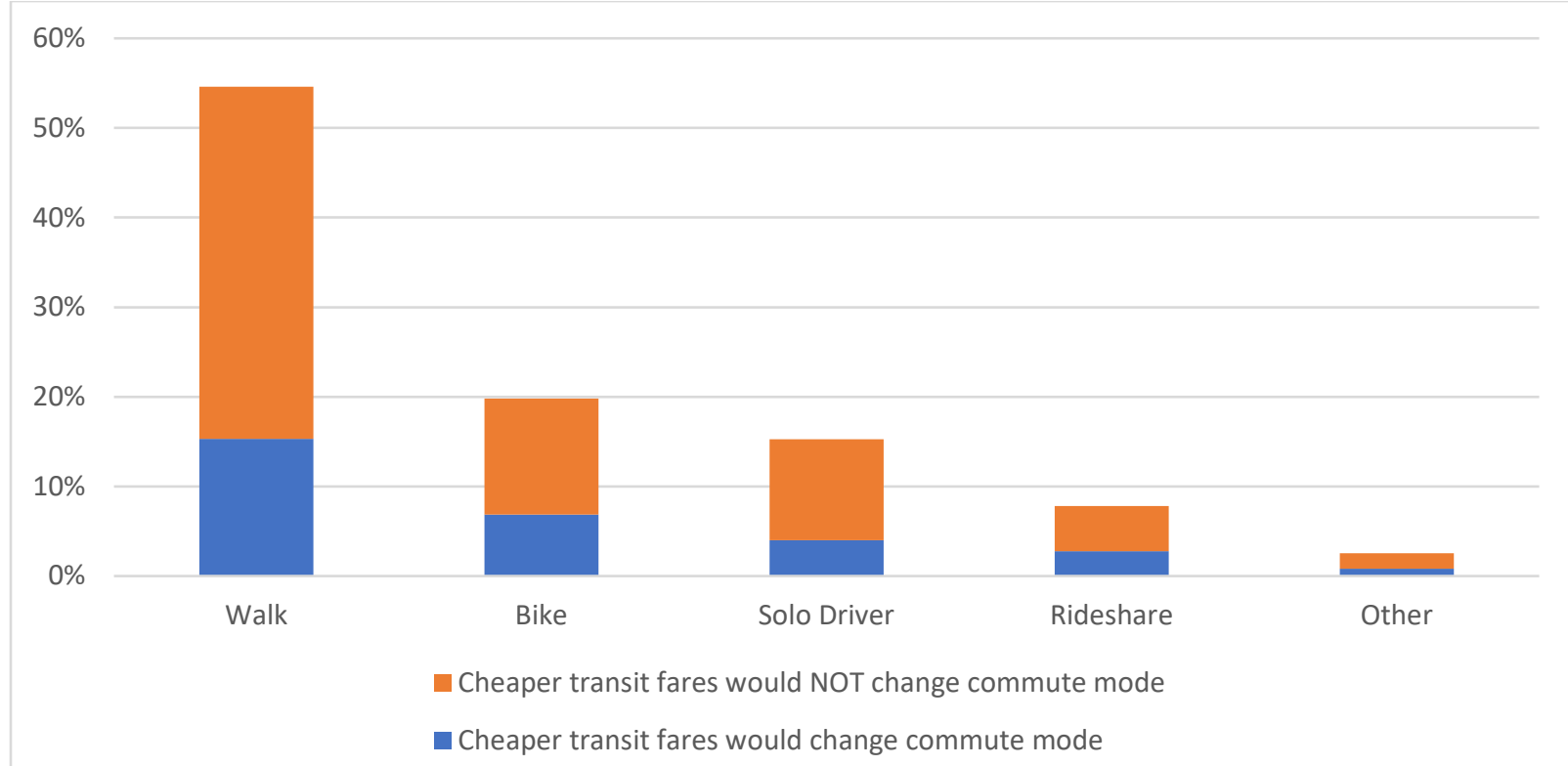


For students that commute to school using transit, more affordable transit fares were the most popular suggestion to improve their transit commute. Almost half identified it as one of their top two alternatives and $26 \%$ ranked it as the most important factor. However, these questions referred only to students' commutes, not discretionary travel.

Figure 5: Transit Commuters' Top Method to Improve Commute

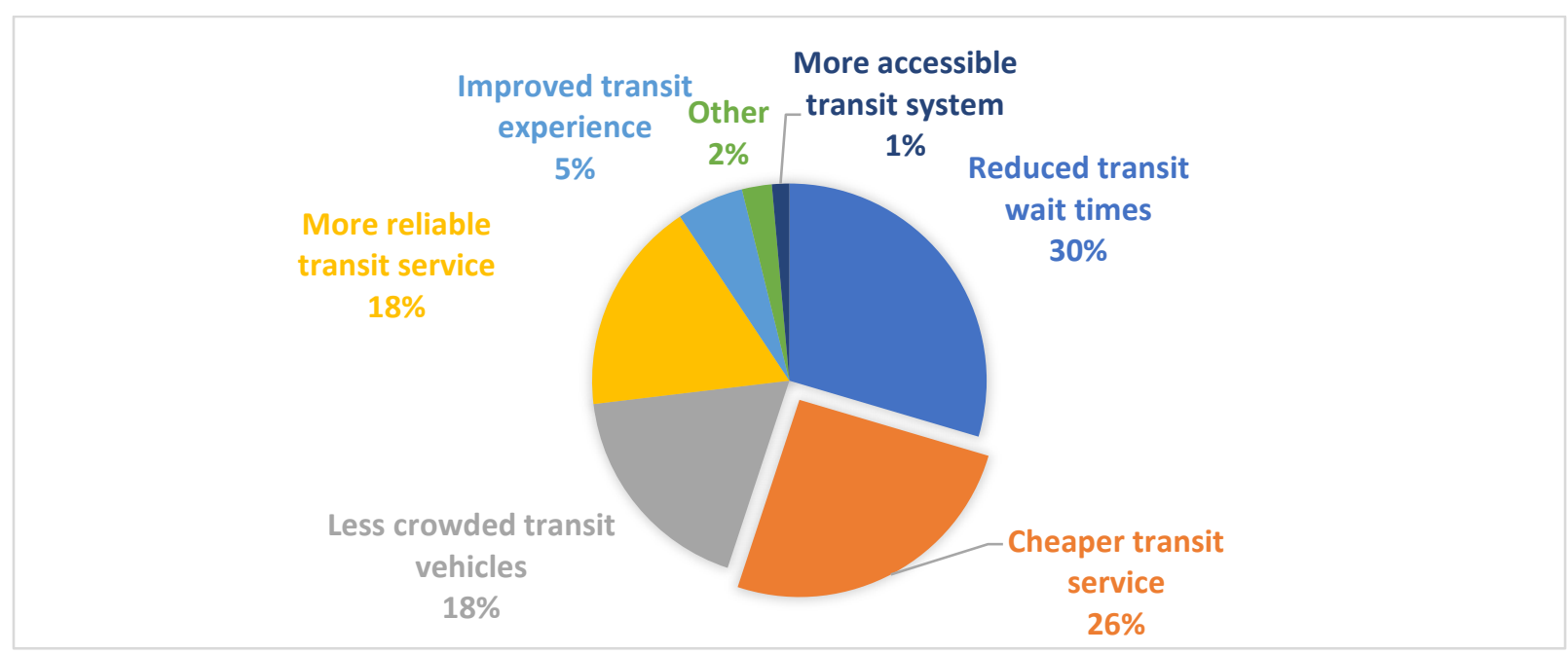

\subsection{Data Cleaning and Downsampling}

The StudentMoveTO dataset includes responses from 15,226 individual students.

Students at the University of Toronto Mississauga campus made up a total of 957 responses which were excluded from this analysis. A further 336 responses were excluded due to crucial variables that were missing or nonsensical responses such as an age below 5 or a home to campus distance above 120 kilometres. Therefore, a total of 13,933 responses were considered.

To improve sample representativeness, the dataset was downsampled to adjust for the student population and gender split of each school. ${ }^{4}$ This was necessary due to an overrepresentation of students at certain campuses, as well as a much higher response rate for females over males that could lead to bias in the model. A representative sample is important for

\footnotetext{
${ }^{4}$ SPSS, which was the software used to create the negative binomial model in this paper, does not allow non-integer weighting for this type of model. This is why downsampling was used rather than weighting.
} 
interpreting subsequent global results which pool and compare all university campuses.

Downsampling does not impact the results of the campus-specific analysis. The proportions were calculated based on 2015 enrolment statistics from Common University Data Ontario from the Council of Ontario Universities. The responses were categorized into subgroups categorized by gender and campus and the responses removed from each subgroup were selected randomly.

Five different random samples were tested on the model and the variations in the coefficients in the results were small. Table 3 shows how many responses were removed from each subgroup. As other data on student enrollment such as location of residence is not publicly available, the responses were downsampled only based on the campus in which they are registered and their gender. The final sample used in the model contained 7,298 responses.

Table 3: Downsampling

\begin{tabular}{|c|c|c|c|c|c|}
\hline Campus & Gender & $\begin{array}{l}\text { Before } \\
\text { Downsampling } \\
\text { (Number) }\end{array}$ & $\begin{array}{l}\text { Before } \\
\text { Downsampling } \\
\text { (\%) }\end{array}$ & $\begin{array}{l}\text { After } \\
\text { Downsampling } \\
\text { (Number) }\end{array}$ & $\begin{array}{l}\text { After } \\
\text { Downsampling } \\
\text { (\%) (\% Change) }\end{array}$ \\
\hline \multirow{3}{*}{$\begin{array}{l}\text { University of } \\
\text { Toronto (St. } \\
\text { George) }\end{array}$} & Male & 2,035 & $14.6 \%$ & 1,085 & $14.9 \%(+0.3 \%)$ \\
\hline & Female & 3,922 & $28.1 \%$ & 1,329 & $18.2 \%(-9.9 \%)$ \\
\hline & Other & 46 & $0.3 \%$ & 17 & $0.2 \%(-0.1 \%)$ \\
\hline \multirow{3}{*}{$\begin{array}{l}\text { University of } \\
\text { Toronto } \\
\text { (Scarborough) } \\
\end{array}$} & Male & 324 & $2.3 \%$ & 252 & $3.5 \%(+1.2 \%)$ \\
\hline & Female & 742 & $5.3 \%$ & 350 & $4.8 \%(-0.5 \%)$ \\
\hline & Other & 6 & $0.0 \%$ & 1 & $0.0 \%(0.0 \%)$ \\
\hline \multirow{3}{*}{$\begin{array}{l}\text { York } \\
\text { University } \\
\text { (Keele) } \\
\end{array}$} & Male & 986 & $7.1 \%$ & 986 & $13.5 \%(+6.4 \%)$ \\
\hline & Female & 2,138 & $15.3 \%$ & 1,263 & $17.3 \%(+2.0 \%)$ \\
\hline & Other & 35 & $0.3 \%$ & 28 & $0.4 \%(+0.1 \%)$ \\
\hline \multirow{3}{*}{$\begin{array}{l}\text { York } \\
\text { University } \\
\text { (Glendon) }\end{array}$} & Male & 61 & $0.4 \%$ & 29 & $0.4 \%(0.0 \%)$ \\
\hline & Female & 271 & $1.9 \%$ & 94 & $1.3 \%(-0.6 \%)$ \\
\hline & Other & 3 & $0.0 \%$ & 1 & $0.0 \%(0.0 \%)$ \\
\hline \multirow{3}{*}{$\begin{array}{l}\text { Ryerson } \\
\text { University }\end{array}$} & Male & 1,016 & $7.3 \%$ & 763 & $10.5 \%(+3.2 \%)$ \\
\hline & Female & 1,867 & $13.4 \%$ & 863 & $11.8 \%(-1.6 \%)$ \\
\hline & Other & 18 & $0.1 \%$ & 11 & $0.2 \%(+0.1 \%)$ \\
\hline \multirow{3}{*}{ OCAD } & Male & 106 & $0.8 \%$ & 69 & $0.9 \%(+0.1 \%)$ \\
\hline & Female & 344 & $2.5 \%$ & 149 & $2.0 \%(-0.5 \%)$ \\
\hline & Other & 13 & $0.1 \%$ & 8 & $0.1 \%(0.0 \%)$ \\
\hline Total & & 13,933 & $100 \%$ & 7,298 & $100 \%$ \\
\hline
\end{tabular}




\subsection{Trip Categorization}

Next, trips were categorized by whether or not they were on TTC. The goal of the modelling was to determine the number of TTC trips expected from each student. While the dataset does include the mode of each trip, it does not differentiate between different transit operators. Therefore, some assumptions were made to isolate TTC trips. In order to do so, trips were assumed to be on TTC if they fit the criteria in Table 4. Since TTC fares are only paid on TTC vehicles within Toronto, any trip that does not begin or end in Toronto is immediately ruled out as a non-TTC trip. While it is possible as of 2018 to pay a TTC fare and use the subway outside Toronto, the subway was exclusively within the City of Toronto at the time of the survey. Also, the TTC is the only transit operator in the region that uses streetcars and subways, therefore any trip using those modes was automatically assumed to be a TTC trip. While using this methodology may exclude a small number of ambiguous trips, the vast majority are accounted for. For example, a trip that begins in Toronto and ends outside Toronto that used a car, a transit bus, and a GO Train could be a TTC trip or could have been a trip on another transit agency. In this paper, it is not assumed to be a TTC trip. Of the 36,740 trips reported by respondents, only $141(0.4 \%)$ are ambiguous like the previous case, so these are unlikely to have had a significant impact on the results. 


\begin{tabular}{|l|c|c|c|c|}
\hline & $\begin{array}{l}\text { Toronto } \\
->\end{array}$ & $\begin{array}{l}\text { Toronto } \\
\text { Toronto }\end{array}$ & $\begin{array}{l}\text { Other }-> \\
\text { Toronto }\end{array}$ & $\begin{array}{l}\text { Other }-> \\
\text { Other }\end{array}$ \\
\hline Use Subway/RT or Streetcar & TTC & TTC & TTC & TTC \\
\hline $\begin{array}{l}\text { Does not include Subway/RT, Streetcar, } \\
\text { or Transit Bus }\end{array}$ & - & - & - & - \\
\hline Only Transit Bus & TTC & TTC & TTC & - \\
\hline $\begin{array}{l}\text { Start with Transit Bus, end with non- } \\
\text { transit mode }\end{array}$ & TTC & TTC & - & - \\
\hline $\begin{array}{l}\text { End with Transit Bus, start with non- } \\
\text { transit mode }\end{array}$ & TTC & - & TTC & - \\
\hline Other Transit Bus & TTC & - & - & - \\
\hline
\end{tabular}

Next, commuting trips were separated from non-commuting trips given the different approaches used to estimate term trip rates for each of these trip types. For the purposes of this study, trips were considered to be commuting if the origin or the destination of the trip was for school purposes. This means that "commuting" trips are really school-related trips. Expectedly, the majority of trip diaries had 0 or 2 school-related trips depending on whether or not they commuted to campus on that particular day.

\subsection{Non-Commuting Travel}

For non-commuting trips, a negative binomial model was estimated using SPSS. For commuting trips that begin or end at school, almost all students took either 0 or 2 trips in their diary depending on whether they attended school that day. These trips are habitual, while noncommuting trips varied significantly. Students that are frequent users of public transit may have recorded zero trips in their trip diary simply out of coincidence. Likewise, an infrequent user of public transit may have recorded several trips on a particular day. For this reason, the number of non-commuting trips taken by each student was estimated using a model to predict the mean number of trips each student takes per day. 
The dependent variable was the number of trips taken that did not originate or end at school. Table 5 shows the variables that were used as predictors in the model. Note that since students took the travel survey on different days, a variable for the day the travel diary was taken is included to control for the differences in travel behaviour based on the day of the week. Binary variables for Monday, Friday, Saturday, and Sunday were included, therefore making midweek the base case. This was done since travel behaviour was observed to be similar on Tuesdays, Wednesdays, and Thursdays.

Table 5: Summary of Variables

\begin{tabular}{|l|c|c|c|c|}
\hline Dependent Variable & Minimum & Maximum & Mean & $\begin{array}{c}\text { Standard } \\
\text { Deviation }\end{array}$ \\
\hline Non-commuting TTC trips & 0 & 7 & 0.31 & 0.770 \\
\hline
\end{tabular}

\begin{tabular}{|c|c|c|}
\hline Categorical Variables & 0 (No) & 1 (Yes) \\
\hline Full Time Status & $9.7 \%$ & $90.3 \%$ \\
\hline Toronto Resident & $32.6 \%$ & $67.4 \%$ \\
\hline Female & $44.5 \%$ & $55.5 \%$ \\
\hline \multicolumn{3}{|l|}{ Trip Diary Day } \\
\hline Monday & & $14.6 \%$ \\
\hline Midweek (Tuesday-Thursday) & & $35.9 \%$ \\
\hline Friday & & $12.0 \%$ \\
\hline Saturday & & $15.8 \%$ \\
\hline Sunday & & $21.7 \%$ \\
\hline Access to Vehicle & $32.9 \%$ & $67.1 \%$ \\
\hline Undergraduate Status & $25.1 \%$ & $74.9 \%$ \\
\hline
\end{tabular}

\begin{tabular}{|l|c|c|c|c|}
\hline Continuous Variables & Minimum & Maximum & Mean & $\begin{array}{c}\text { Standard } \\
\text { Deviation }\end{array}$ \\
\hline $\begin{array}{l}\text { Natural Log of Residential Density (per } \\
\text { sq. km)* }\end{array}$ & 0.10 & 3.69 & 2.64 & 0.55 \\
\hline $\begin{array}{l}\text { Natural Log of Street Density (km per } \\
\text { sq. km)* }\end{array}$ & 1.55 & 11.02 & 8.40 & 1.15 \\
\hline
\end{tabular}

* Continuous variables were calculated based on the census tract of residence 
Some variables that were significant in studies from the literature review were tested, but ultimately not included in the final model due to a lack of significance. Multicollinearity between some variables led them to be excluded from the final model. Listed below are some of the variables that were considered, but ultimately excluded from the model:

- Age under 23: This variable had a correlation coefficient of 0.565 with undergraduate status. This is likely because students above the age threshold are more likely to be working towards a second degree.

- Distance from campus: The natural log of distance from campus had high correlation coefficients with several variables. Notably, the natural log of population density ($0.282)$, household vehicle status (0.563), and residence in Toronto (-0.598). Three of the campuses in the study are located downtown and a large concentration of the student body attend these campuses. This means that students living further from their school are less likely to live in Toronto, live in less dense areas and in more auto-centric environments.

- Distance from a subway station under 800 metres: This was highly correlated with the natural log of population density (0.470), household vehicle ownership (-0.443), and Toronto residency (0.423). Since subway stations were only located within the City of Toronto at the time of the survey and population density tends to be higher near stations, this variable was rendered insignificant.

- Median household income in census tract of residence: This variable was found to be significant in research (Lavery et al., 2013). It can also act as a proxy for household income of respondent since that data was missing from the survey. However, it was not 
significant when added to the model. In particular, it is correlated with household vehicle ownership (0.392) and residency in Toronto (-0.549).

- Household size: This was also found to be insignificant in the model. It is correlated with several variables including household vehicle availability $(0.371)$. This is likely due to larger households among students that live with their parents, who are in turn more likely to own a vehicle.

When deciding which variables to exclude from the model, the variance of the model was taken into account.

Once predicted values for the number of daily TTC non-commuting trips were calculated for each student, they were adjusted to represent the number of TTC trips on a midweek day in order to control for variation across days of the week. The following formula was used:

\section{Midweek day TTC trips $=$ Predicted Value $/ \exp \left(b_{(\text {trip diary day })}\right)$}

$\exp \left(b_{\text {trip diary day }}\right)$ represents the odds ratio for the day the trip diary was taken. For example, if the odds ratio for a particular day is 1.2 , it means that a student is predicted to take $20 \%$ more TTC trips on that day. To get an estimate for trips on a midweek day, the predicted value from the model needs to be divided by 1.2 .

For example, if a student was predicted to take 1.5 TTC trips and their travel diary was taken on a Sunday, 1.5 was divided by $\exp \left(\mathrm{b}_{(\text {Sunday })}\right)$ to estimate the number of trips that student would take on a typical midweek day.

Next, the total number of weekly trips was calculated with the following formula:

$$
\begin{gathered}
\text { Weekly Trips } \left.=t^{*} 3+t^{*} \exp \left(b_{\text {Sunday }}\right)\right)+t^{*} \exp \left(b_{\text {Monday }}\right)+t^{*} \exp \left(b_{(\text {Friday })}+t^{*} \exp \left(b_{(\text {Saturday })}\right)\right. \\
t=\text { Midweek day TTC trips }
\end{gathered}
$$

That number was multiplied by 17.4. This is the average number of weeks in a four month period or standard school term for which students would be entitled to a U-Pass while 
enrolled. This method assumes that students take a similar number of discretionary trips each week throughout the year. This gives the total number of non-commuting TTC trips. The negative binomial model does not inflate or deflate the total number of TTC trips, therefore the mean number of trips estimated and the mean number of trips reported by students in the trip diary is equal.

Since 2015 when the StudentMoveTO survey was conducted, TTC fare policy was changed with the implementation of free 2-hour transfers. Essentially, any trip taken within 2 hours of the beginning of another trip is free. In order to model this, the model was run again, but TTC trips that were started within 2 hours of the beginning of another TTC trip were not included. Both versions of the results are discussed.

\subsection{Commuting Travel}

The number of school-related TTC trips taken by each student was determined using descriptive responses from the survey instead of a model. This was done because commuting trips are more habitual than other types of trips. In the survey, students reported the different modes of transportation they use to get to school, as well as the number of times they go to campus in a typical week. If a student responded that they use the subway, a local bus or streetcar to get to school, they were assumed to use TTC to get to school since it would be impossible to access the campuses in this study using local transit without using TTC. The exception to this rule is York University Keele, which is accessible using other local transit services. For York University Keele students, they were only assumed to use TTC to get to school if they fulfill the requirement above and also live in the City of Toronto.

If a student typically uses transit to get to school and reports commuting to campus 4 times per week, it was assumed that they take 8 school-related trips per week over the 13 weeks of school in a term for a total of 104 trips. The 13 weeks of school includes 12 weeks of 
instruction plus an additional week to account for exam period travel. However, some respondents reported that they walk or cycle to campus as their main mode of commuting (the mode that covers the most distance), but also use transit on a typical day. This scenario is unlikely, so it is clear some students misinterpreted the survey question. Therefore, students that reported walking or cycling to campus as their main mode of commuting were assumed to not use TTC to get to school, even if they indicated they also use local transit on a typical day. This adjustment was made in order to avoid overcounting the number of commuting trips on TTC.

This method has limitations including a trust in the self-reported number of school trips from respondents. This limitation can be avoided by modelling school and discretionary travel together, however that would introduce the assumption that the number of TTC trips is the same across instructional weeks and during school breaks. By separating them, school trips can be assumed to not happen outside of the 13 weeks of the school term for a more accurate estimate of total TTC trips taken.

Since 2015, when the data was collected, the TTC's fare structure changed such that TTC trips using a Presto card (a smart card fare payment) that included connections to GO Transit (the regional transit service) were discounted to $\$ 1.50$ instead of $\$ 3.00$. As approximately one-third of students from outside of Toronto reported GO usage, this change affects the balance of comparative benefits from the proposed U-Pass system. In order to account for this, a second set of results was created, taking into account commuters that habitually use GO and TTC to get to school, recognizing that their TTC commuting cost will be half. These are counted as half trips. Non-commuting trips, however, were assumed to all be at full price as the negative binomial model is a model for count data and half price trips could not be accommodated. However, only 
a small number non-commuting trips from the dataset would be impacted, therefore it was concluded to have little impact on the results.

\subsection{Comparing U-Pass Benefits and Costs}

Using model-derived estimates of discretionary transit trip-taking and estimates of TTCbased commuting to school derived from descriptive statistics, total term TTC trip rate estimates were calculated. Results are presented for the aggregate expected effects of the U-Pass program to explore whether the student body would benefit from the U-Pass or whether they would be committed to spending more on the U-Pass relative to their expected transit use. While previous research has established that U-Passes increase transit ridership (Brown, 2001; Miller, 2001), this

analysis does not consider the impact of latent demand. It solely considers the travel behaviour of students as it was in 2015.

Finally, a sub-market analysis is presented that examines the differences in TTC use between different campuses, residential locations, and types of commuters. This examines not only the proportions of students that benefit and do not, but also by the quantity of dollars saved or lost for each sub-market. Furthermore, it considers the impacts of a U-Pass on students under the fare policy as it was in 2015 and with 2019 fare policy. 


\section{Results and Analysis}

Three areas of results and analysis are presented here. First, the results of the negative binomial model are described along with the number of non-commuting TTC trips that were estimated. Second, the number of commuting trips per student as calculated from the descriptive statistics is analyzed. Using findings on student transit use for commuting and non-commuting purposes, a global analysis is presented illustrating how different transit fare structures impact students across the major universities. Finally, a sub-market analysis was conducted that broke down results on the relative benefits and costs born by students based on their campus, residential location, and existing commute mode.

\subsection{Non-Commuting Travel}

Table 6 shows the results of the negative binomial model that estimated TTC trips with and without consideration for 2-hour transfers. Figure 6 displays the number of trips estimated for each student. The coefficient represents the impact of that variable on the number of noncommuting TTC trips taken by each student. 
Table 6: Predictors of Negative Binomial Model

\begin{tabular}{|c|c|c|c|c|}
\hline \multirow[t]{2}{*}{ Parameter } & \multicolumn{2}{|c|}{$\begin{array}{l}\text { Without Free 2-hour } \\
\text { Transfers }\end{array}$} & \multicolumn{2}{|c|}{ With Free 2-Hour Transfers } \\
\hline & Coefficient & P-value & B & Sig. \\
\hline (Intercept) & -1.01 & 0.00 & -1.10 & 0.00 \\
\hline Friday Trip Diary & 0.16 & 0.04 & 0.18 & 0.03 \\
\hline Monday Trip Diary & -0.21 & 0.01 & -0.26 & 0.00 \\
\hline Saturday Trip Diary & 0.15 & 0.03 & 0.15 & 0.05 \\
\hline Sunday Trip Diary & -0.15 & 0.03 & -0.15 & 0.05 \\
\hline Midweek Trip Diary & ref & & ref & \\
\hline Full Time Student $(0=n o)^{*}$ & 0.29 & 0.00 & 0.35 & 0.00 \\
\hline Undergraduate $(0=\text { no })^{*}$ & 0.10 & 0.09 & 0.13 & 0.03 \\
\hline $\begin{array}{l}\text { Toronto Residence } \\
(0=\mathrm{no})^{*}\end{array}$ & -1.42 & 0.00 & -1.38 & 0.00 \\
\hline Female $(0=\text { no })^{*}$ & -0.09 & 0.06 & -0.08 & 0.15 \\
\hline Access to Vehicle $(0=n o)^{*}$ & 0.30 & 0.00 & 0.28 & 0.00 \\
\hline In(Street Density) & -0.33 & 0.00 & -0.31 & 0.00 \\
\hline In(Population Density) & 0.10 & 0.01 & 0.09 & 0.03 \\
\hline
\end{tabular}

*Compared to reference category $1=$ yes

All variables are significant at the 0.05 -level with the exception of gender and undergraduate status which are marginally significant at the 0.10 -level. The estimated effect of residing in Toronto is expected to have a significant impact on transit use by TTC. When controlling for the other variables, students that live outside the City of Toronto take less than a quarter of the trips taken by Toronto residents. Having access to a household vehicle was associated with less non-commuting TTC travel. While street density was associated with less transit use, population density was associated with increased transit use. Population density is likely a proxy for transit quality, while denser street environments are conducive to active transportation over transit, particularly in neighborhoods proximate to major universities. The mean number of expected non-commuting trips is 37.9 per term. When trips within a 2-hour window are excluded, the results are similar, but the mean number of non-commuting trips predicted is reduced to 32.8. Note, however, that gender is no longer significant at the 0.10 -level after those trips are removed. 
Figure 6: Number of Estimated Non-Commuting TTC Trips per Student per Term
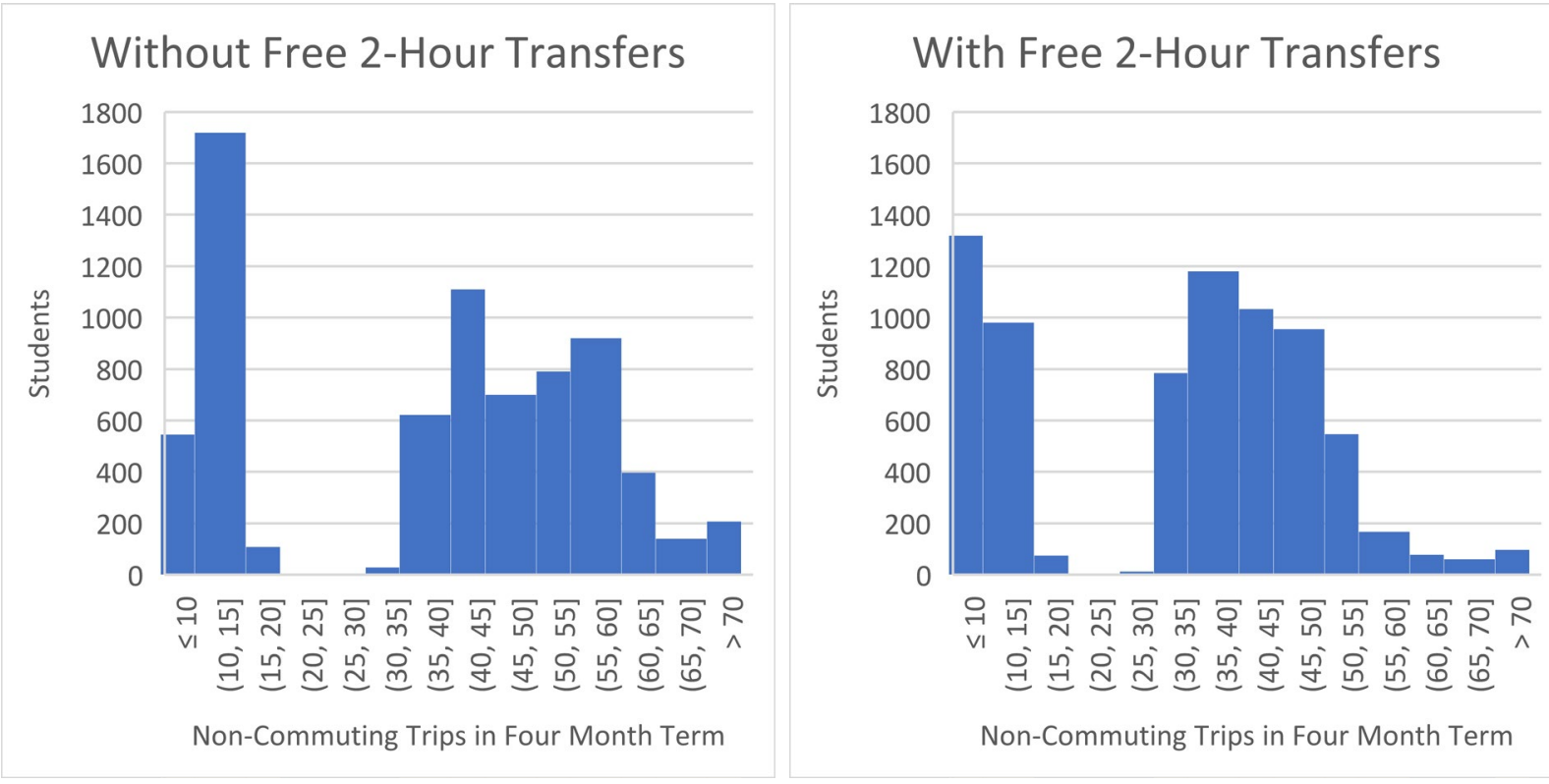

Figure 6 suggests that TTC use is bimodal and most students take less than 15 or between 35 and 60 non-commuting TTC trips per term. The second histogram shows a similar bimodal distribution, however there is a smaller proportion of students with predicted trips above 50 .

\subsection{Commuting Trips}

For commuting trips, $52 \%$ of students across all campuses used TTC to get to school, even if they may combine with another mode such as cycling or GO Transit. The frequency of commute to school differs for each student as described in Table 7.

Table 7: Frequency of TTC Commute to Campus

\begin{tabular}{|r|r|r|r|}
\hline $\begin{array}{l}\text { Weekly Frequency } \\
\text { of Commute to } \\
\text { Campus }\end{array}$ & $\begin{array}{l}\text { Resulting TTC } \\
\text { Trips (One Term) }\end{array}$ & $\begin{array}{l}\text { Full Price } \\
\text { Equivalent } \\
\text { of Trips }\end{array}$ & \% of Sample \\
\hline Non-TTC Commuter & N/A & $\$ 0$ & $48.2 \%$ \\
\hline 1 & 26 & $\$ 78$ & $1.7 \%$ \\
\hline 2 & 52 & $\$ 156$ & $4.2 \%$ \\
\hline 3 & 78 & $\$ 312$ & $9.1 \%$ \\
\hline 4 & 104 & $\$ 390$ & $14.4 \%$ \\
\hline 5 & 130 & $\$ 468$ & $3.3 \%$ \\
\hline 6 & 156 & $\$ 546$ & $0.7 \%$ \\
\hline 7 & 182 & &
\end{tabular}


Note that in order to benefit from the TTC U-Pass, a student would need to take 94 TTC trips to make up for the $\$ 280$ cost per term. This means that based on commuting trips alone, an estimated $37 \%$ of students would benefit from traveling to school 4 times or more per week. However, $7 \%$ of the sample also use GO Transit in their commute, so if the half price trips are taken into consideration, that number is reduced to $30 \%$.

\subsection{Global Analysis}

Figure 7 shows the total number of TTC trips estimated for each student in one term in the following four scenarios:

1. Assuming 2015 Fare Policy

2. 2-Hour transfers are free

3. TTC trips combined with GO Transit are half price

4. Assuming 2019 Fare Policy (both conditions 2 and 3) 


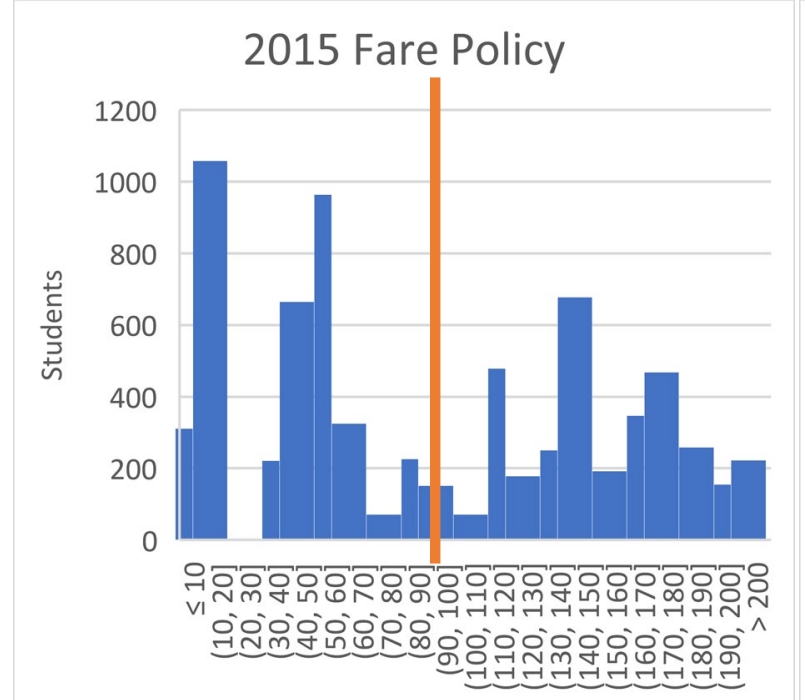

Trips in Four Month Term

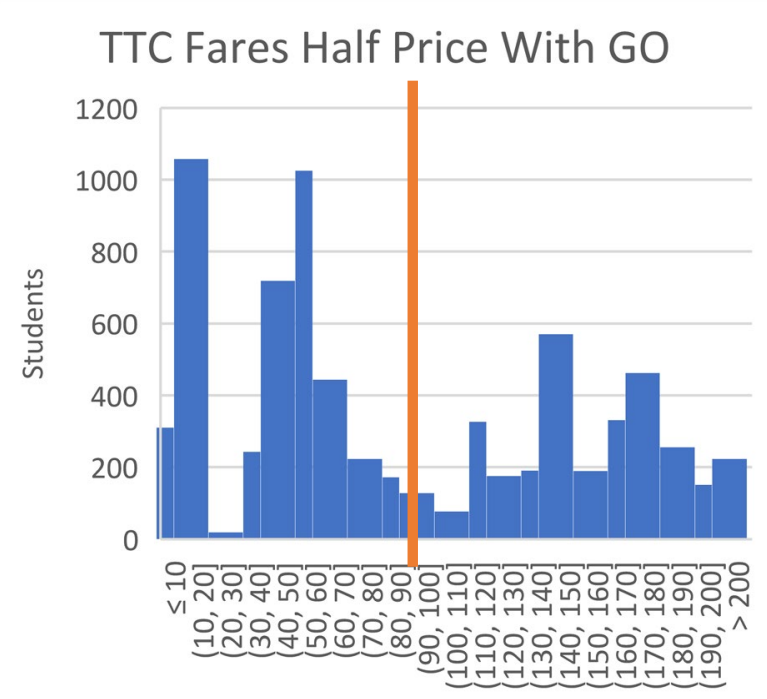

Trips in Four Month Term

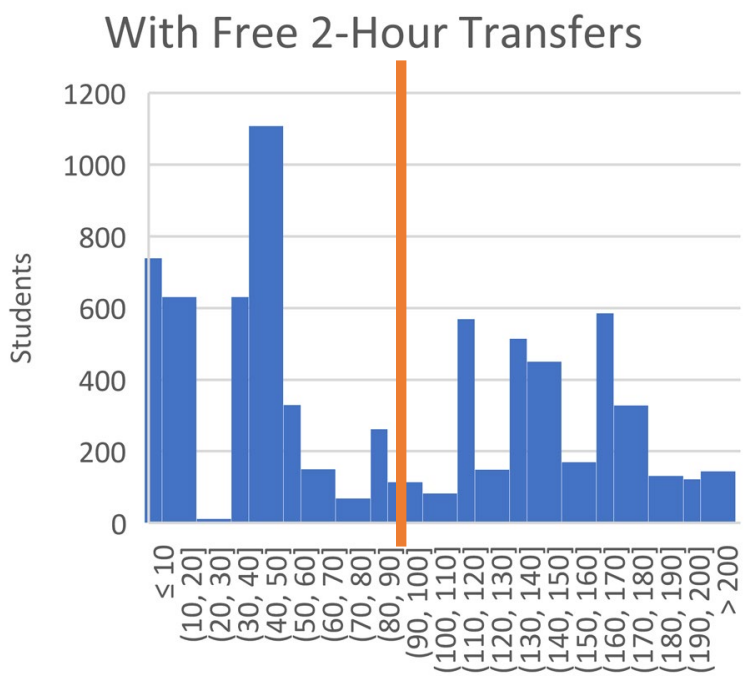

Trips in Four Month Term

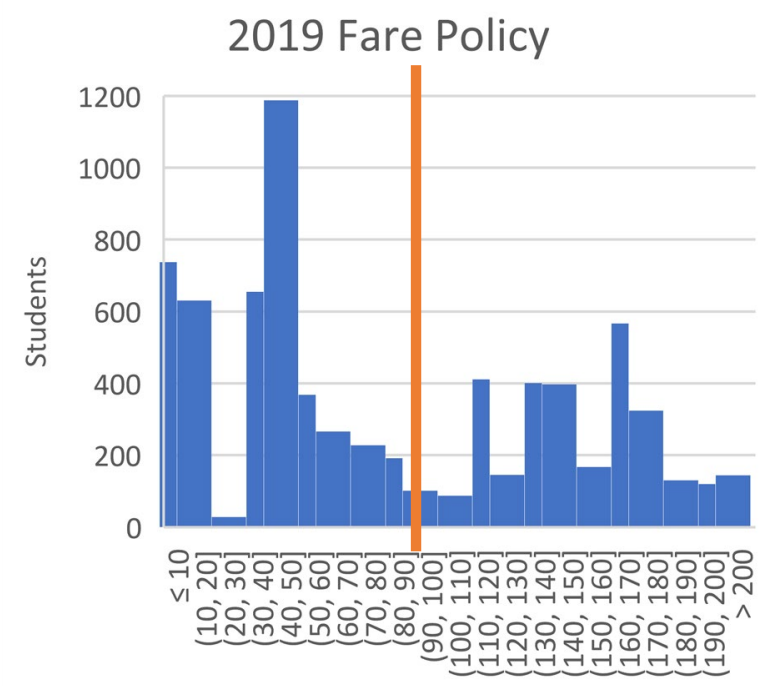

Trips in Four Month Term

* Orange line shows the rough breakeven point for the U-Pass to be worthwhile

While the distribution changes based on the application of different scenarios, they are generally trimodal with a mode below 20, a mode between 40 and 60, and a mode between 140 and 170. Note that the breakeven point for the U-Pass to be worthwhile for an individual student is 94 trips, which is in the "valleys" of these distributions, so small changes in the price of the UPass would have little impact on the number of students that would benefit. Figure 8 summarizes students by their estimated transit use for each scenario. 
Figure 8: Estimated TTC Trips Categorized by Usage Level

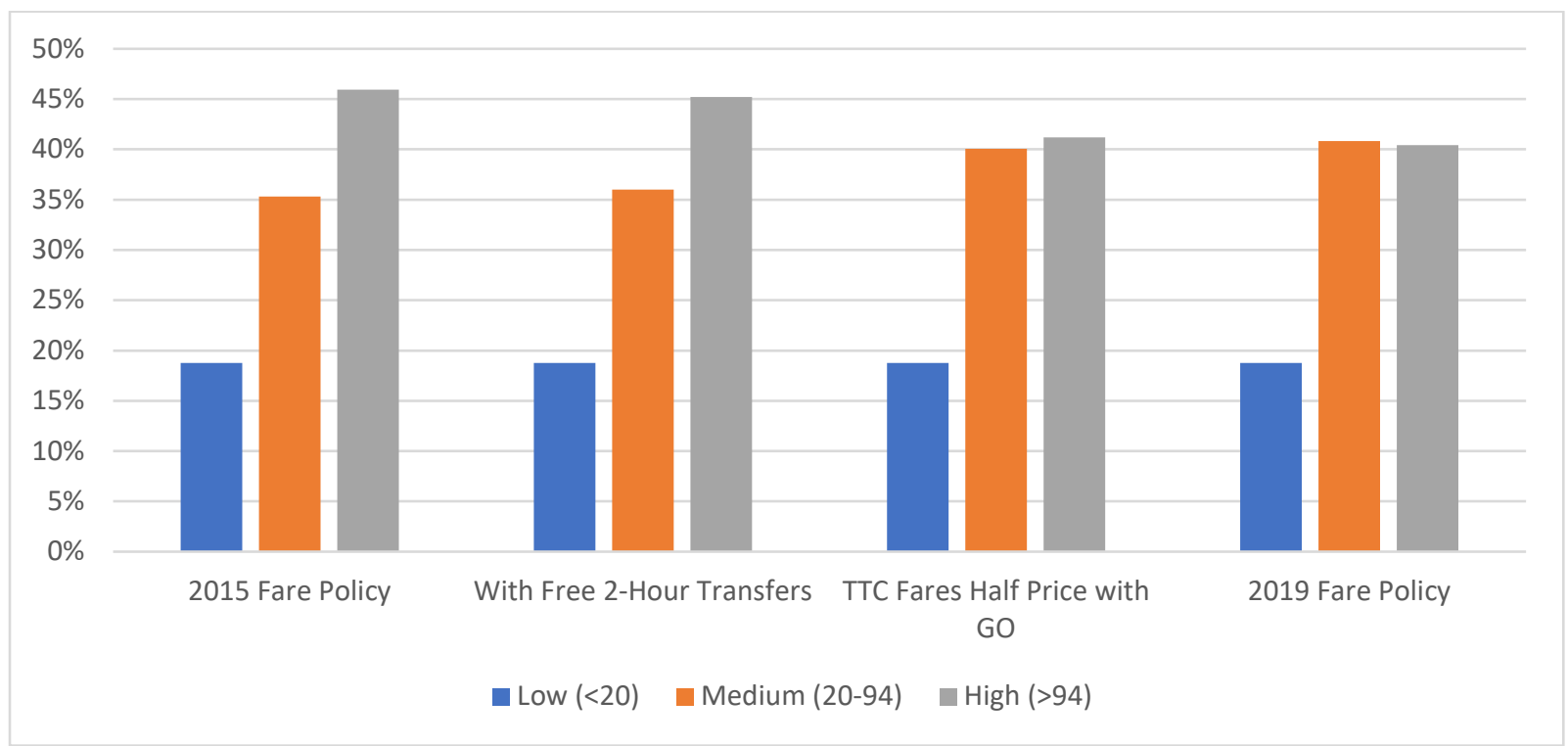

Students in the "High" category are those that would benefit from the U-Pass. With or without free 2-hour transfers, $45-46 \%$ of students benefit from the U-Pass. However, the impact of the GO Transit discount is more significant, decreasing the proportion of students that benefit to $41 \%$. Note that this analysis is global across all campuses in the study. The impact of the GO Transit discount is felt more or less strongly on different campuses depending on the number of GO Transit commuters. GO Transit mainly serves the downtown campuses through Union Station and York University Keele through the bus terminal. This is explored further in section 5.4.1.

Furthermore, this analysis assumes there is no induced demand as a result of the discount. In reality, there would be some increase in the number of TTC trips.

\subsection{Sub-Market Analysis}

\subsubsection{Campuses}

This section seeks to examine subgroups of the population to see who is expected to benefit and who is not. The results here are examined based on fare policy as it was in 2015 and with the 2019 fare policy including GO Transit discounts and free 2-hour transfers. 
Figure 9: Estimated TTC Trips Categorized by Usage Level by Campus
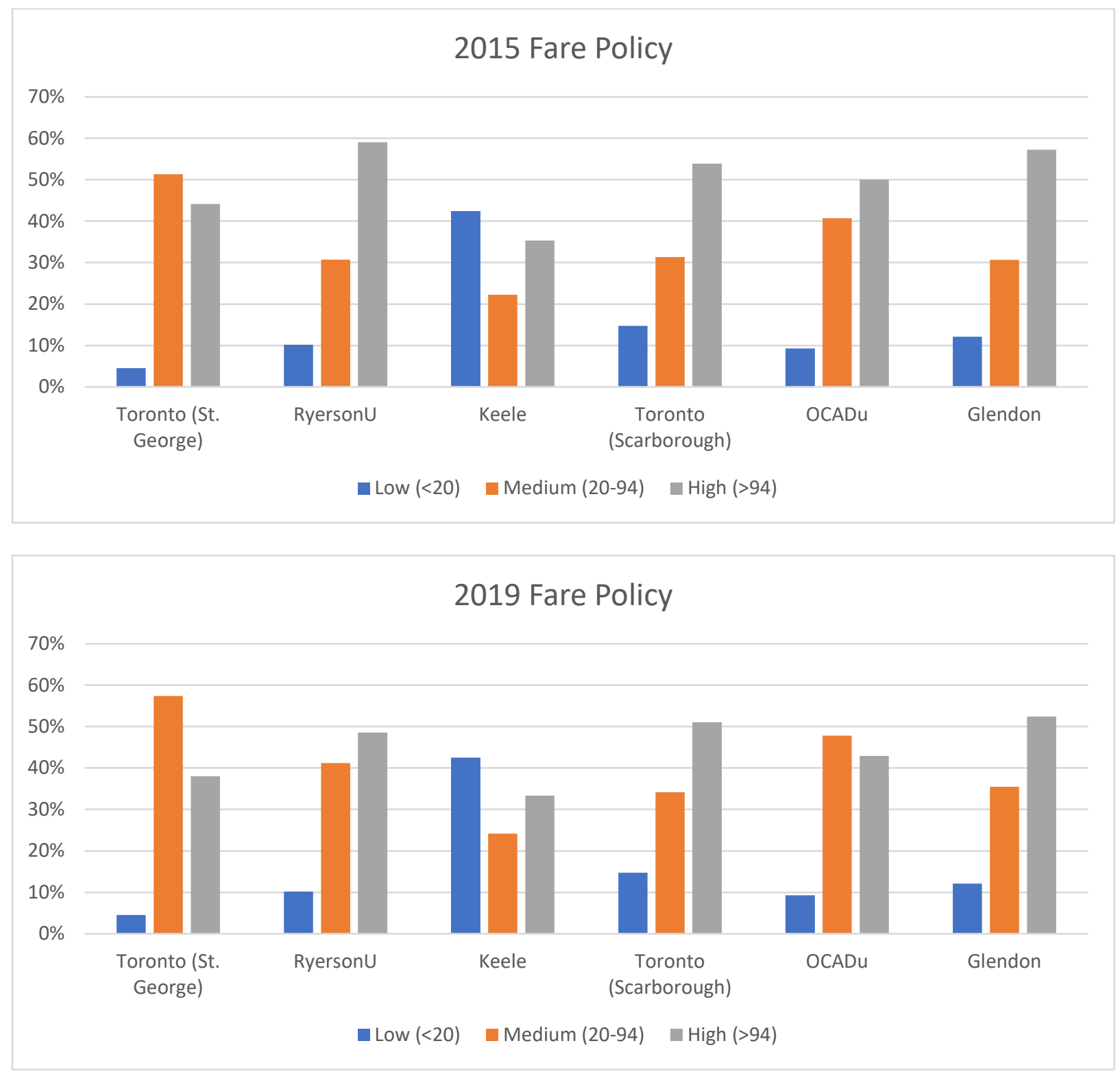

Note that the U-Pass is more beneficial to the student body on some campuses than others. It is the suburban campuses like York University Glendon and the University of Toronto Scarborough Campus that stand to benefit the most due to high TTC ridership. Ryerson University is notable for being an urban campus with a high number of GO Transit commuters. Therefore, without the GO Transit discount, $60 \%$ of students stand to benefit from the U-Pass. When TTC trips combined with GO Transit are already discounted, that number drops under 
$50 \%$. It is notable that the TTC U-Pass referendum passed at Ryerson University, despite this study's estimate that most students would not benefit. However, most students would benefit under the simpler 2015 fare structure. This suggests that as the fare policy has become more complex, students may not be tuned into these small changes that can make the difference between the U-Pass being in their interest or not.

Figure 10: Mean Savings or Loss from U-Pass by Campus Attended (Four Month Period)

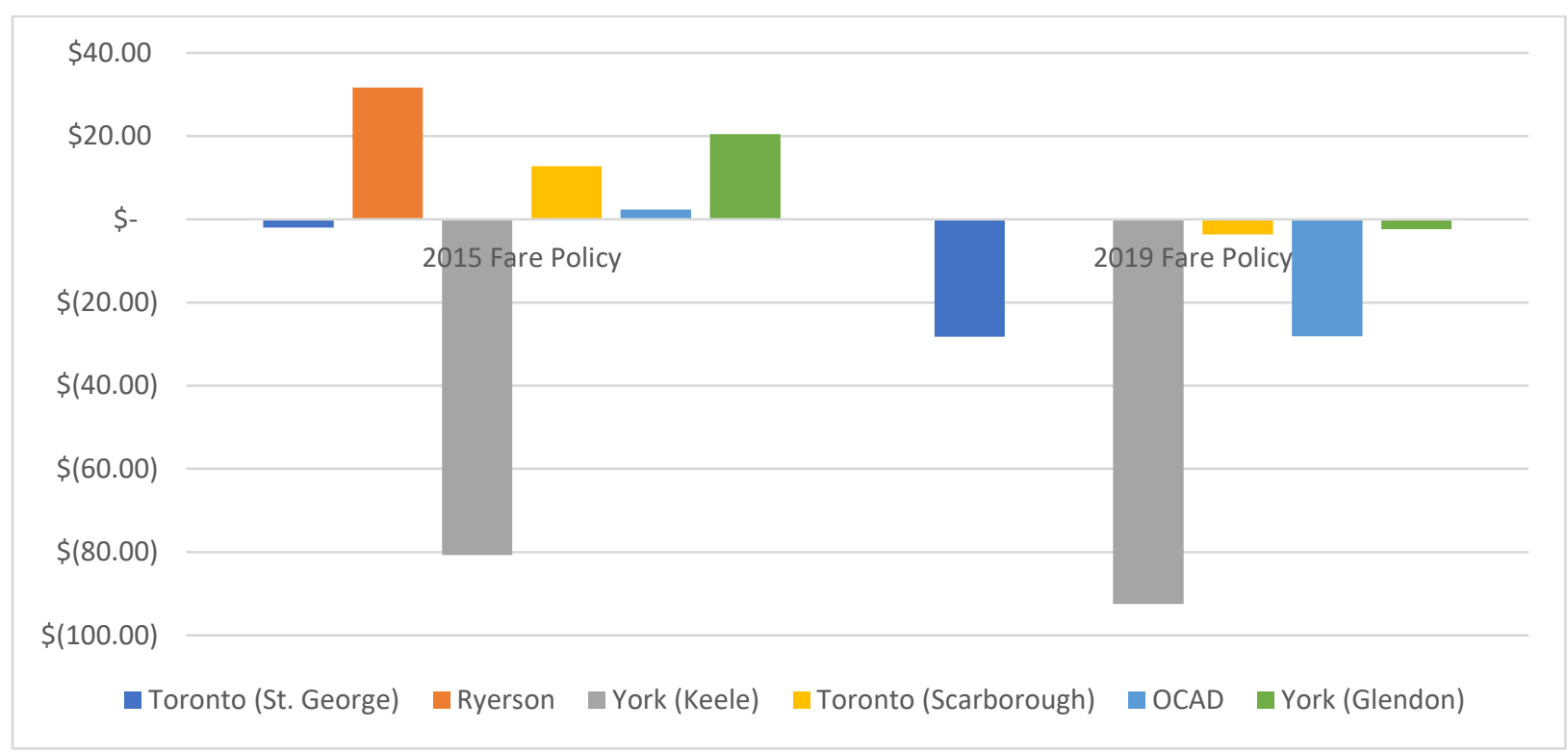

The average savings or loss for students categorized by campus is under $\$ 40$ per term in both scenarios at all campuses with the exception of York University Keele Campus where losses are in excess of $\$ 80$. Under the current fare structure, the average student loses on all campuses, however the mean loss is very close to zero at Ryerson University, Toronto Scarborough Campus, and York University Glendon Campus. The benefit of the program to students is greatly diminished when the current fare structure is taken into account, largely due to the half price fares when GO is combined with TTC. Note that the maximum amount a student can save from the U-Pass is $\$ 46.75$ monthly since a monthly TTC pass for post-secondary 
students is currently $\$ 116.75$ and the U-Pass is $\$ 70$ monthly. This assumes that students always purchase a monthly TTC pass when it would benefit them.

\subsubsection{Residential Location}

In the negative binomial model that estimated the number of non-commuting TTC trips, the variable with the highest coefficient was residency in Toronto. Furthermore, population density at a student's residence had a positive impact on the number of trips, while street density had a negative impact. Residential location is an important predictor of the number of TTC trips a student takes.

The model estimates that only $13-16 \%$ of students living outside of the City of Toronto would benefit from the U-Pass program, while 58\% are low users of TTC. This is unsurprising since these students live outside of the TTC service area. For students living in the City of Toronto, 46-52\% would benefit depending on the fare policy.

Figure 11: TTC Trips Categorized by Residential Location

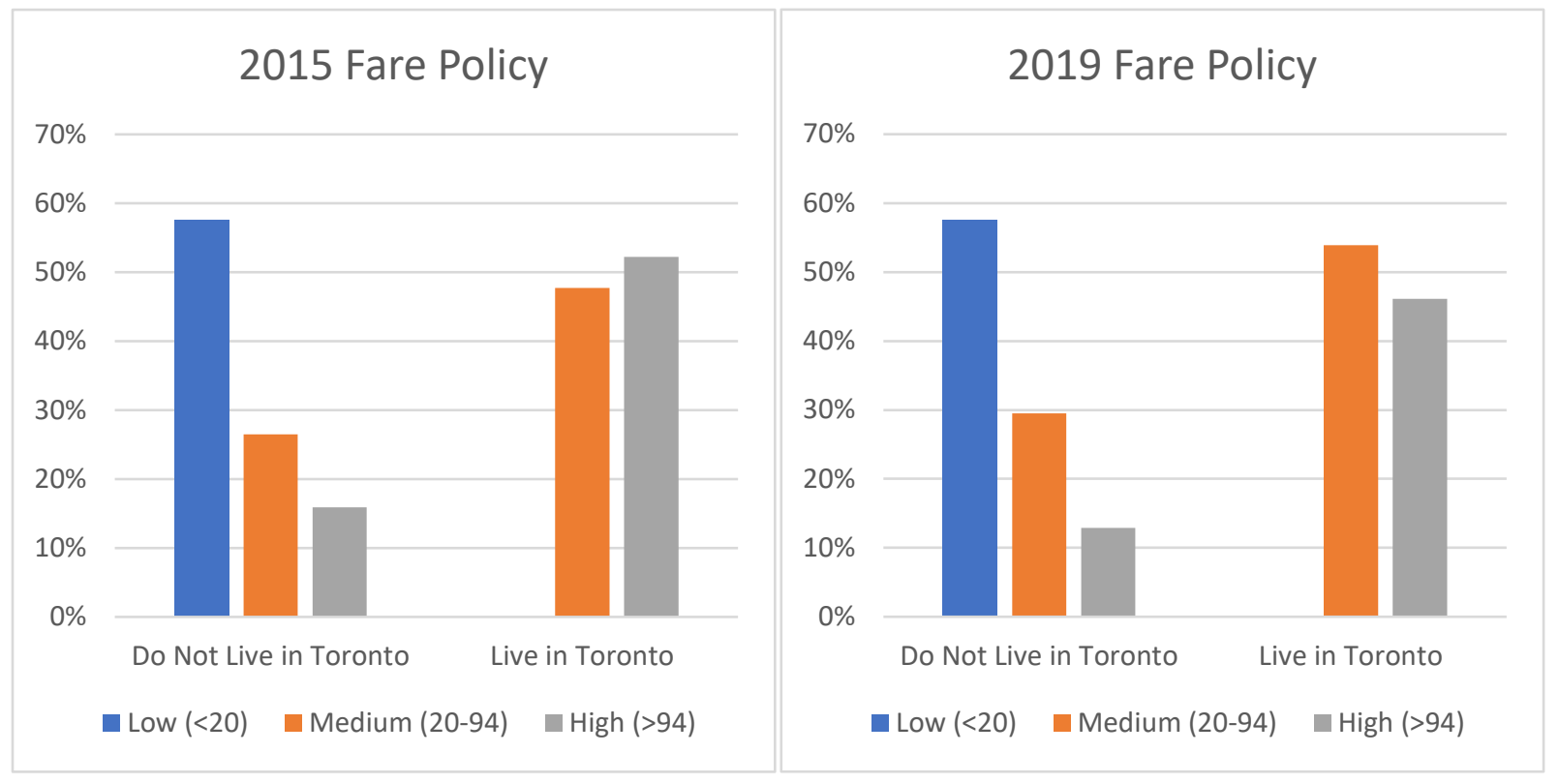


Note that the impact of the fare policy assumed has only a minor impact on the proportion of students that benefit from the U-Pass in either geography (Figure 11). This is due to the fact that the 94 trip threshold falls between the two modes on the bimodal distribution of TTC trip rates shown on the histogram in Figure 7 from Section 5.3. The average savings or loss are impacted substantially however (Figure 12).

Figure 12: Savings or Losses for Toronto and Non-Toronto Residents

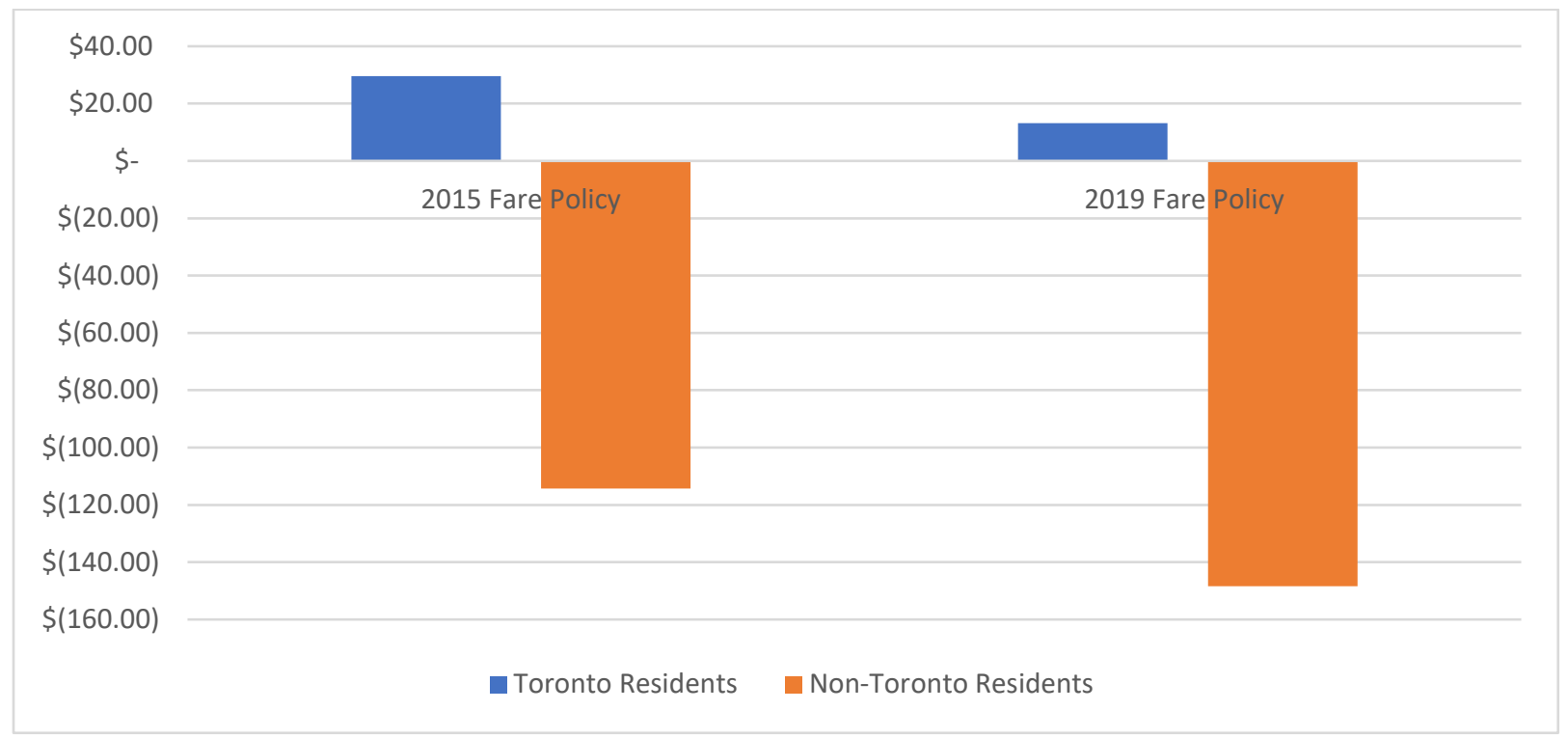

Figure 13 shows where high, medium, and low users of TTC live. Each dot represents one person. In general, low TTC users live outside of the City of Toronto and high users of TTC live inside the City of Toronto. Medium users of TTC are scattered throughout the region, however there are significant clusters of medium users around each campus, including within the downtown core. These students are largely those that commute by walking. Note that a small number of students live outside of the boundaries of this map, however most are displayed within the frame. 


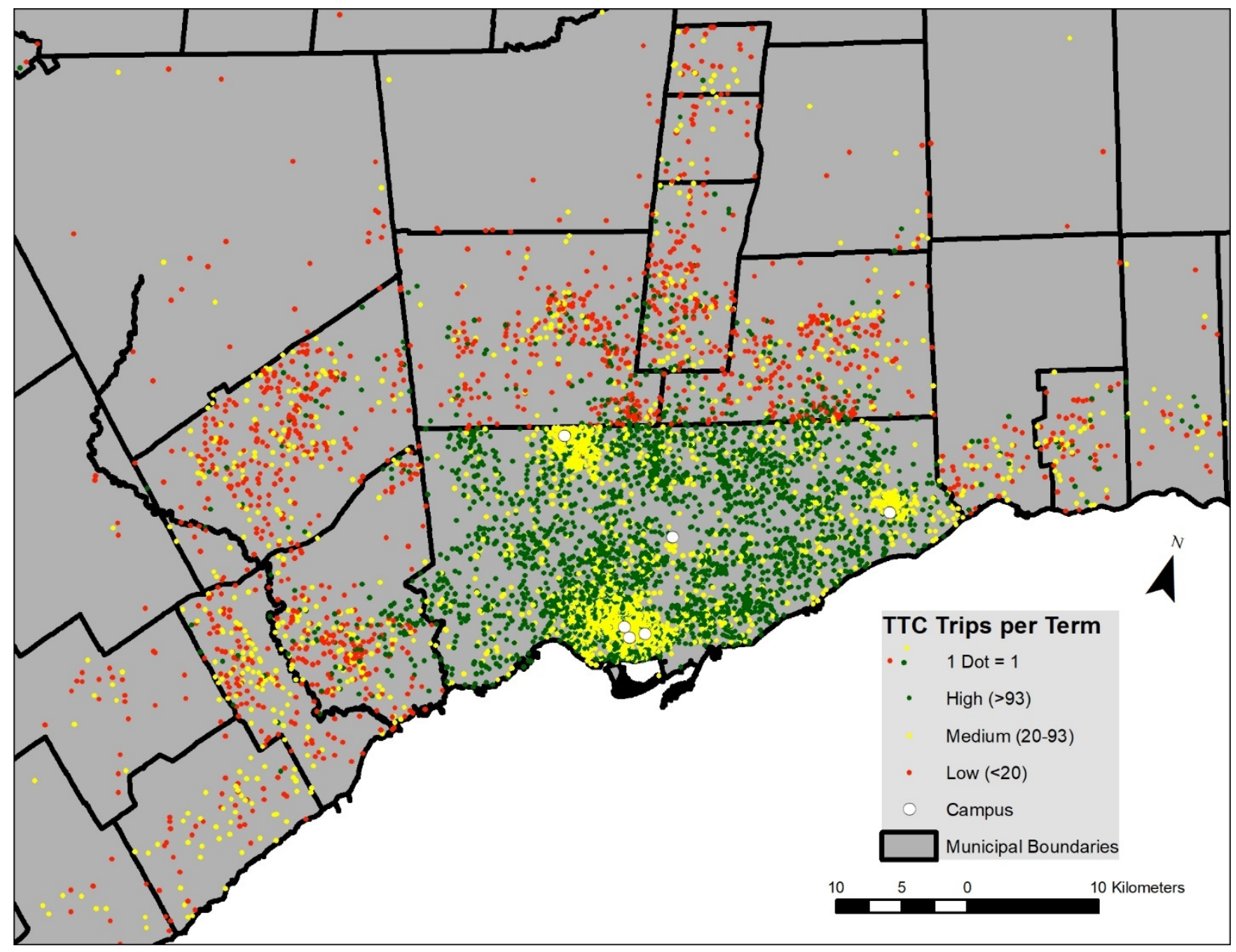

\subsubsection{Commute Mode}

When examining the results by typical fall commuting mode, we find that most students that use local transit to get to school and a smaller portion of regional transit users would stand to benefit. Drivers and passengers benefit the least. While students that walk and bike to school do not benefit, they are almost entirely "medium" users of TTC. This means that while they do not use it enough to spend $\$ 70$ in a month, they use it for a significant amount of discretionary travel. This is echoed in literature finding that users of active transportation have higher modality than non-users of active transportation (Lavery et al., 2013). 
Figure 14: TTC Trips by Regular Commute Mode to School
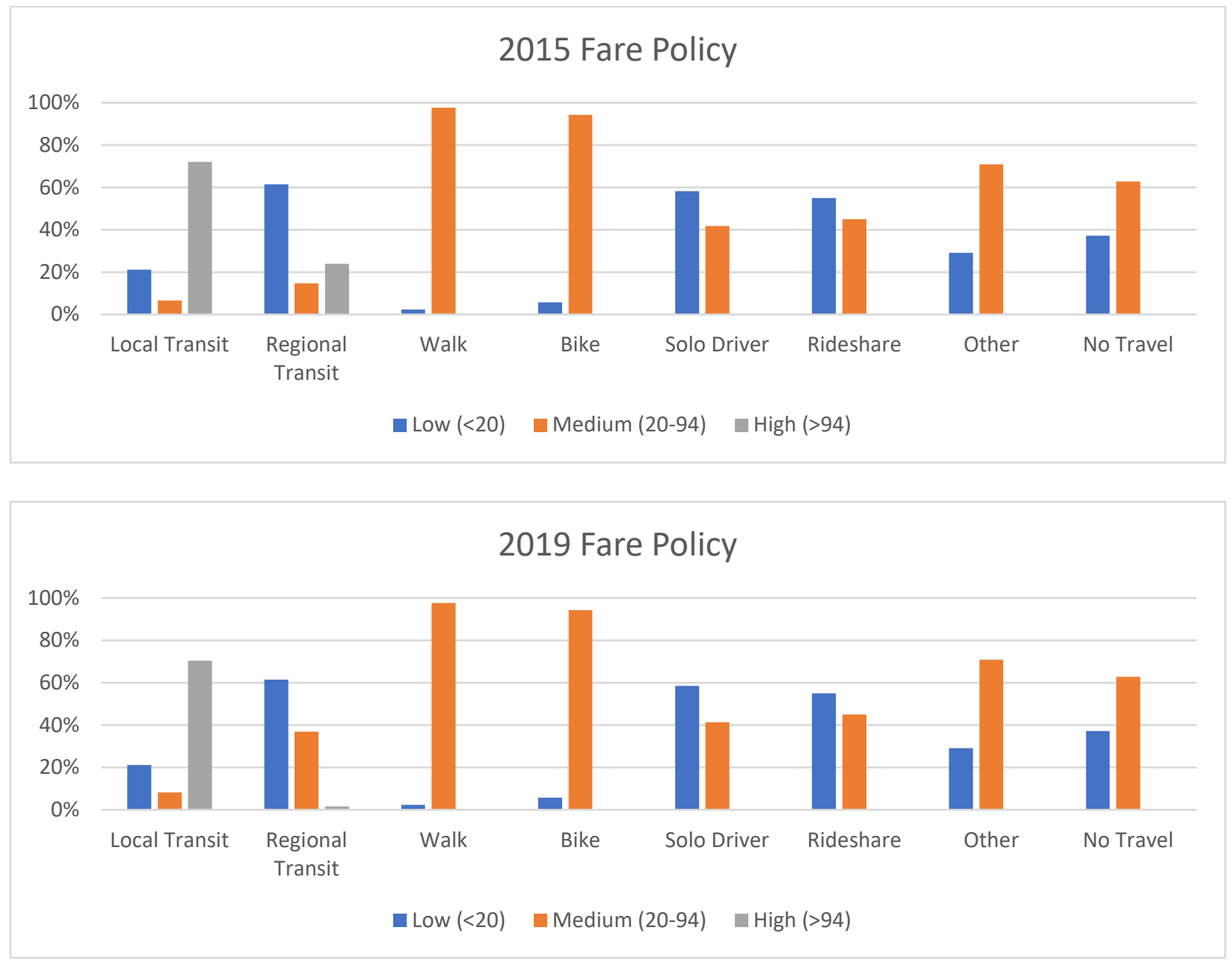

Figure 15: Average Benefit or Loss by Regular Commute Mode to School

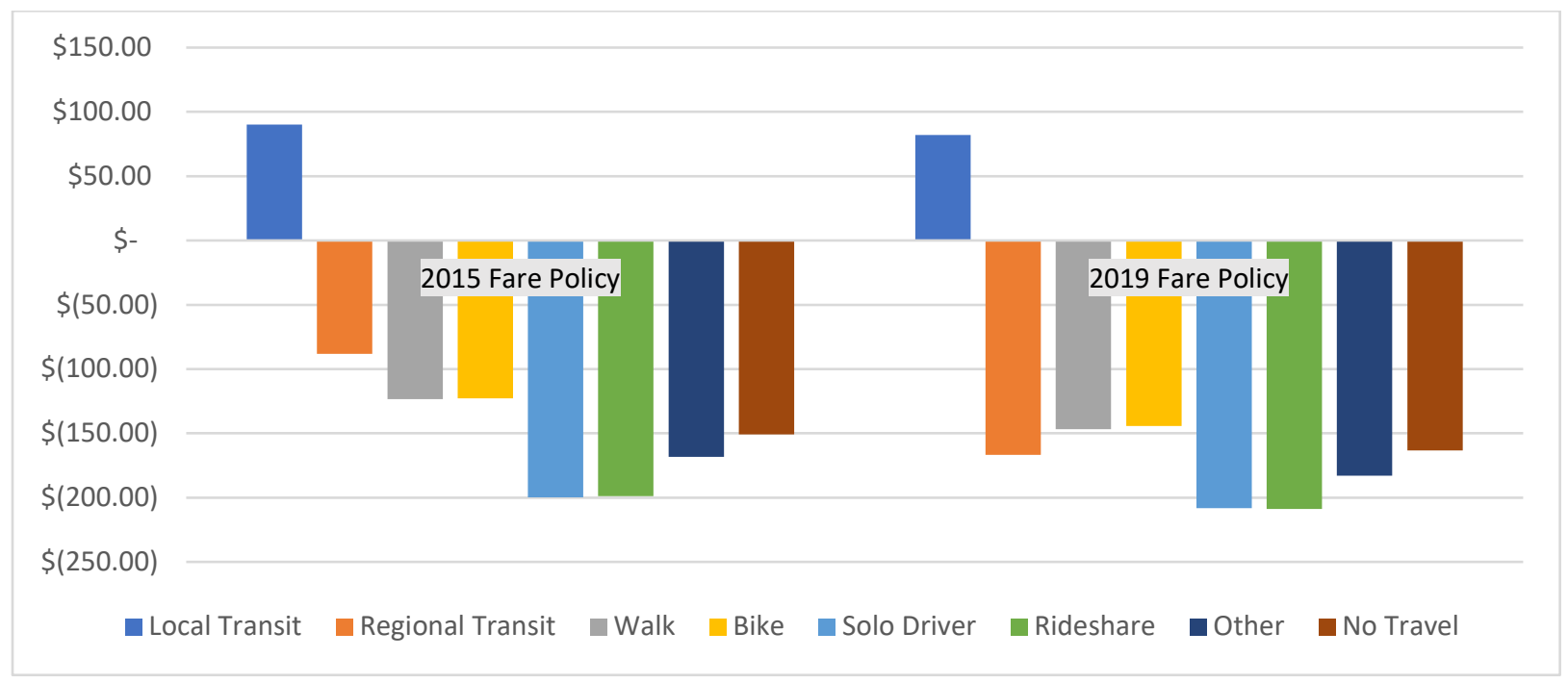




\section{Policy Implications}

\subsection{U-Pass Price}

At $\$ 70$ per month, the TTC U-Pass is more expensive than most others across Canada and the United States (Brown et al., 2001; TTC, 2017). The price point was selected in order to be revenue-neutral for the TTC (TTC, 2018). Therefore, the program is not designed to be a subsidy for student transit, but a redistribution of resources from students that do not use TTC often to those that do.

Ryerson University already passed the proposal, while the University of Toronto St. George campus rejected it. The model and analysis in this paper predict that $49 \%$ and $38 \%$ of students at each campus would benefit respectively given the 2019 fare policy (see Figure 9). The only large campus that has yet to vote is York University Keele and seeing as it benefits less students there than at the University of Toronto St. George, it would be unlikely to pass. The large proportion of benefiting students at the University of Toronto Scarborough and York University Glendon suggest that a referendum could be successful at those campuses. However, note that there is still a mean loss per student at these campuses. The proportion of students benefiting at OCAD falls between Ryerson University and the University of Toronto St. George, so a referendum could go either way.

Due to the bimodal distribution of the number of trips taken by students, a modest change in the price of the U-Pass does little to change the number of students that benefit. This is reflected in Figure 16 that shows the proportion of students that would benefit at each campus at different price points. To make a substantial difference in the number of students benefiting, the U-Pass price would need to be reduced to less than $\$ 40$ per month. With the exception of York University Keele campus, the vast majority of students would benefit at that price. In other words, structural factors like living in Toronto or commuting using TTC are large indicators of 
whether or not one uses TTC enough to benefit. As a result, small changes in price have little impact on the number of students that benefit.

At York University Keele campus, TTC use is low enough that that the pass would need to be less than $\$ 30$ per month to benefit most students, most likely making it financially infeasible.

Figure 16: Monthly TTC Spending by Campus

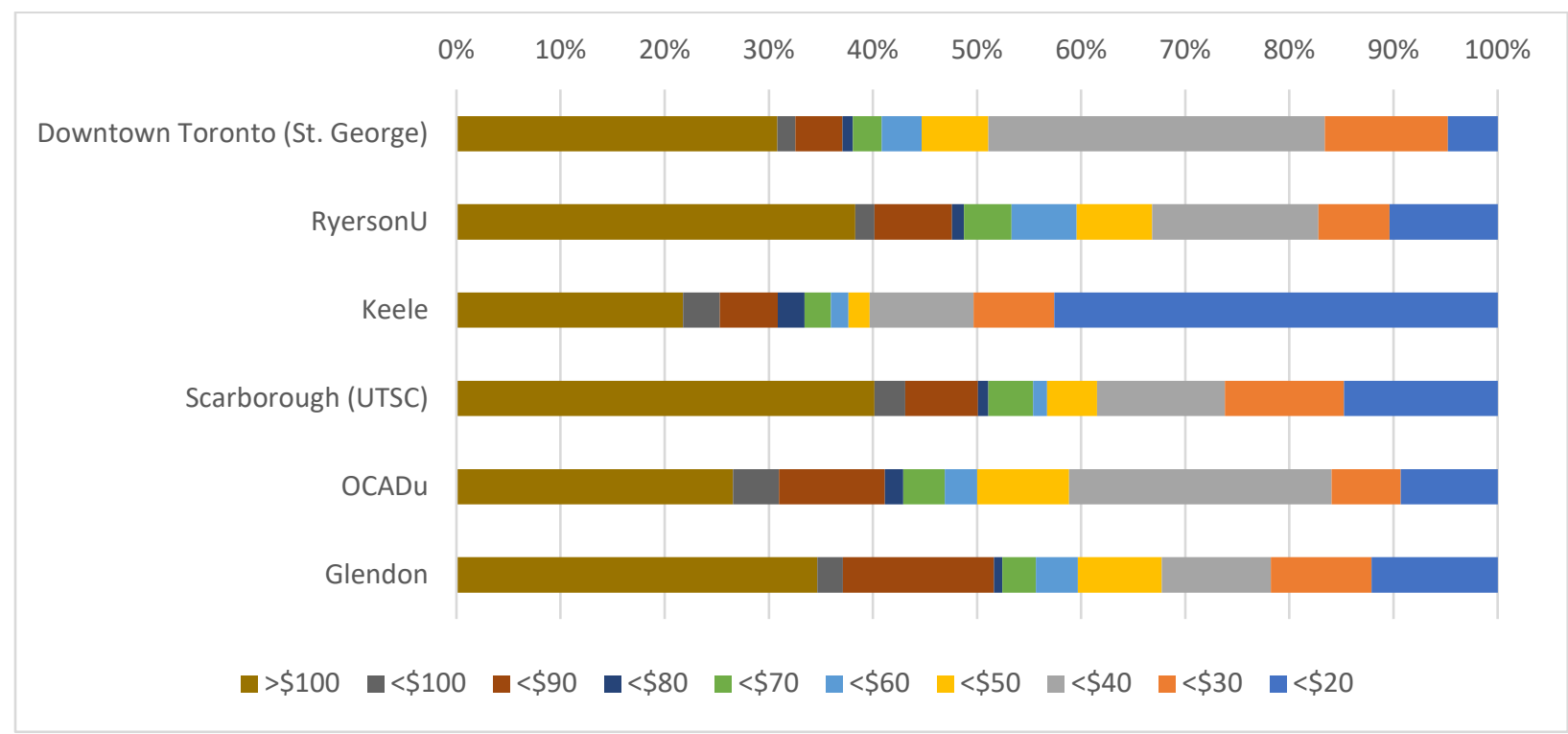

\subsection{Equity}

A U-Pass will always benefit some students over others. However, U-Pass programs typically have a variety of funding sources including student fees, parking revenues, university funds, or other government revenues (Miller, 2001), while the TTC U-Pass is funded solely by student fees. Since this is the only source of funding and the program was designed by the TTC to be revenue neutral (TTC, 2018), it follows that some students must be subsidizing others. This could be justified if there is evidence that the subsidized students are in need, however, with limited data on income in the StudentMoveTO dataset, those conclusions cannot be drawn in this study. Goals of the U-Pass program imply a goal of shifting from market-based equity (each 
student paying for his or her own transit fares) towards equity of opportunity (each student would have equal opportunity to use TTC) (Taylor and Norton, 2009). However, as discussed above, this shift also entails significant sources of inequity relating to geography (residential location and whether one resides inside or outside of Toronto) and user groups (modes and campuses).

Students that bike and walk to get to school are almost entirely "medium" users of TTC (20-94 TTC trips over a school term). This means that while they use transit at least somewhat frequently, they do not use it enough to benefit from the U-Pass at its current price. Those using active transportation are disincentivized from doing so, rather than rewarded for making more sustainable transportation choices. They may be encouraged to shift towards using transit rather than active transportation.

Some subgroups clearly benefit over others. For one, students within the City of Toronto take more commuting and non-commuting TTC trips than students that live outside of the City of Toronto. This is most likely because they live within the TTC service zone and therefore have better access. Since transit fares are not integrated across the region, Toronto is a special case for U-Pass. Toronto is a city of 2.7 million people, but the Greater Toronto Area has over double the population. This means that a considerable number of students are not able to use TTC for trips that originate from their home. If they choose to use a transit service in their home municipality, they must pay full price, while also paying for the U-Pass that subsidizes the travel of those living in the City of Toronto. Referring to the map in Figure 13, the students that benefit the most are those that live within the City of Toronto, but far enough from campus that they are unable or unwilling to walk or bike to school. If students that live outside of the service area could opt-out 
of the pass, it would ease the geographic inequity. This would, however, significantly reduce the revenue stream to the TTC.

\subsection{Funding}

The price of the TTC U-Pass is high because it is designed by the TTC to be revenue neutral and does not include any funding sources beyond student fees. If other university funding sources like parking revenues were included in the funding package for U-Pass, such as in the case of other universities (Brown et al., 2001, Miller et al., 2001), it could reduce the cost for students. This does mean, however, reallocating university revenues. Furthermore, this does not solve the equity issues discussed in Section 6.2.

\subsection{Goals of U-Pass}

Whether the U-Pass for the Greater Toronto Area is a sound policy depends on the goals of the program. TTC documents make reference to making transportation more affordable for students, but do not discuss goals of the program further (TTC, 2017; TTC, 2018). Implicitly, this policy is an attempt to shift from market-based sources of equity (transit users benefiting from fares that they pay) towards equity of opportunity, enabling all post-secondary students equal access to transit by providing all with TTC passes.

With only $8 \%$ of students reporting driving to school, much of the increase in ridership from the U-Pass program would likely come from trips that would formerly have been made using active transportation. Often, U-Pass programs are framed as a transportation demand management (TDM) measure to curb vehicle use, but in this context, students are already using transit services and active transportation. Therefore, ridership growth may occur, but at the expense of active transportation.

From the perspective of transit operators, U-Pass programs are often offered because they are perceived to increase transit ridership, provide guaranteed revenue, and improve overall 
transit service (Brown et al., 2001). The current TTC U-Pass program meets the first two of these objectives. As for improving overall transit service, the TTC does anticipate the need for additional operational spending to keep up with a predicted $15 \%$ increase in demand from implementation of the U-Pass program (TTC, 2018). It follows that the increased operational spending would mean some additional service that could be enjoyed by all transit users, not solely students. For the transit operator, the $\$ 70$ U-Pass is a golden opportunity. Universities typically offer U-Pass because they reduce demand for parking, increase access to housing and employment, support recruitment, and increase transportation equity (Brown et al., 2001). In the Toronto context, there is less potential than in other areas to reduce demand for parking, since there are already few students driving to campus. However, the UPass could be argued to increase access to housing and employment by removing a financial barrier to other parts of the city inaccessible using active transportation. As for transportation equity, this is debatable for the reasons discussed in Section 6.2. 


\section{Limitations and Further Study}

This study examined who benefits and who does not from the TTC U-Pass. However, it was limited in scope and further study would be helpful to better understand the impacts of the U-Pass.

First, this study did not include a ridership forecast. The analysis here is based on the number of trips and commuting behaviour reported by students in 2015. In reality, the implementation of a U-Pass would be expected to increased transit ridership (Meyer et al., 1998; Meyer et al., 2006; Boyd, 2003; Brown, 2003). This issue is complex because it begs the question whether someone benefits from the U-Pass if they take more trips as a result of the free pass, pushing them over the $\$ 70$ threshold. Work on a second StudentMoveTO survey has already commenced for data collection in 2019. Further study could examine how ridership is impacted at campuses that implement the U-Pass versus those that do not when the new data is available.

Second, the discussion of equity was limited due to limited data on income in the dataset. This paper suggests that the U-Pass ensures that some students are subsidizing others. However, it did not discuss whether those students being subsidized are in need. Further study on the income of students and the location of their residences would add clarity to the conversation on equity.

Lastly, new infrastructure has increased the utility of the TTC system. For example, a subway extension into Vaughan was recently completed and offers a new opportunity for students living in that area to use TTC services. This project and others likely had an impact of students' travel behaviour. The second iteration of the StudentMoveTO dataset could offer insight into how travel behaviour has changed since 2015. 


\section{Conclusion}

U-Passes are a popular measure to increase transit ridership, offer a guaranteed revenue stream to transit agencies, and reduce transportation costs for students. However, Toronto and this U-Pass proposal are unique due to the high fee and the lack of integration in transit fares across the region.

This paper found that approximately $40 \%$ of students at Toronto universities take enough TTC trips to justify the $\$ 70$ per month cost of U-Pass. This varies across campuses as well. Students at campuses with more TTC commuters like Ryerson University and the University of Toronto Scarborough have much higher TTC use. York University Keele students have much lower TTC use due to its proximity to the TTC service boundary, meaning that students are more likely to travel on other transit agencies. The University of Toronto St. George has lower TTC use as well, however this is due a large number of active transportation users that live in the downtown core.

Given the high price of the U-Pass compared with other programs in North America, it is unlikely that a student will benefit from the U-Pass if they do not commute using TTC. Most students that benefit from the U-Pass live far enough from their campus that they are unable or unwilling to use active transportation to travel to school, but also live within the City of Toronto.

A reduction in the fee or an opt-out provision for students that do not live within the TTC service area would make the U-Pass beneficial for students that do not live within the City of Toronto and for those that are moderate users of transit. However, additional funding from parking revenues, general university funds, or other government funding would be necessary to support the program if these modifications were made and revenue neutrality remains a priority for the TTC. 
Another solution to broaden the appeal of the pass would be to add other transit operators into the scheme. If local transit operators outside of the City of Toronto or GO Transit were to bundle their services into the pass, it would be useful for students that do not live within the City of Toronto. Also, students that live in the outer suburbs would at least have the option of using local transit in their local communities at no additional cost. However, the funding for these trips still needs to come from somewhere. Additional funding or an increase in the price of the U-Pass would be required.

The TTC U-Pass makes transit more affordable, but only for some. The fact that it is predicated on being revenue neutral for the TTC means that the low and moderate users of transit that commute using active transportation or live outside of Toronto are subsidizing TTC commuters. Integration with other transit agencies, a reduction in the price of the U-Pass, or an opt-out provision for students living outside of Toronto would make the TTC pass more equitable and beneficial to more students. Someone needs to pay for the revenue loss from the UPass, but there is little justification for that to be non-TTC commuter students. After all, there are no free rides. 


\section{References}

Akar, G., Flynn, C., \& Namgung, M. (2012). Travel choices and links to transportation demand management: Case study at Ohio State University. Transportation Research Record: Journal of the Transportation Research Board, (2319), 77-85.

Badoe, D. A., \& Yendeti, M. K. (2007). Impact of transit-pass ownership on daily number of trips made by urban public transit. Journal of Urban Planning and Development, 133(4), 242249.

Baig, F. (2018, March 20). TTC board approves U-Pass for post-secondary students. Toronto Star. Retrieved from: https://www.thestar.com

Brown, J., Hess, D. B., \& Shoup, D. (2003). Fare-free public transit at universities: An evaluation. Journal of Planning Education and Research, 23(1), 69-82.

Brown, J., Hess, D. B., \& Shoup, D. (2001). Unlimited access. Transportation, 28(3), 233-267.

Boyd, B., Chow, M., Johnson, R., \& Smith, A. (2003). Analysis of effects of fare-free transit program on student commuting mode shares: BruinGo at University of California at Los Angeles. Transportation Research Record: Journal of the Transportation Research Board, (1835), 101-110.

Busch-Geertsema, A., \& Lanzendorf, M. (2017). From university to work life - jumping behind the wheel? explaining mode change of students making the transition to professional life. Transportation Research Part A, 106, 181-196.

Cervero, R. (2002). Induced travel demand: Research design, empirical evidence, and normative policies. Journal of Planning Literature, 17(1), 3-20.

Cervero, R., \& Kockelman, K. (1997). Travel demand and the 3Ds: density, diversity, and design. Transportation Research Part D: Transport and Environment, 2(3), 199-219.

Collins, C. M., \& Chambers, S. M. (2005). Psychological and Situational Influences on Commuter-Transport-Mode Choice. Environment and Behavior, 37(5), 640-661.

Daisy, N. S., Hafezi, M. H., Liu, L., \& Millward, H. (2018). Understanding and modeling the activity-travel behavior of university commuters at a large Canadian university. Journal of Urban Planning and Development, 144(2), 04018006.

Delmelle, E.M., Delmelle, E.C., 2012. Exploring spatio-temporal commuting patterns in a university environment. Transp. Policy 21, 1-9.

Eom, J. K., Stone, J. R., \& Kang, K. (2010). Empirical case study of Spatial-Temporal student activity population. Transportation Research Record: Journal of the Transportation Research Board, 2157(1), 11-21. 
Hafezi, M. H., Daisy, N. S., Liu, L., \& Millward, H. (2018). Daily activity and travel sequences of students, faculty and staff at a large Canadian university. Transportation Planning and Technology, 41(5), 536-556.

Hasnine, M. S., Lin, T., Weiss, A., \& Habib, K. N. (2018). Determinants of travel mode choices of post-secondary students in a large metropolitan area: The case of the city of Toronto. Journal of Transport Geography, 70(Complete), 161-171

Khattak, A., Wang, X., Son, S., Agnello, P., 2011. Travel by university students in Virginia: is this travel different from travel by the general population? Transp. Res. Rec. 2255, 137-145.

Lavery, T.A., Páez, A., Kanaroglou, P.S., 2013. Driving out of choices: an investigation of transport modality in a university sample. Transp. Res. A Policy Pract. 57, 37-46.

Limanond, T., Jomnonkwao, S., Watthanaklang, D., Ratanavaraha, V., \& Siridhara, S. (2011). How vehicle ownership affect time utilization on study, leisure, social activities, and academic performance of university students? A case study of engineering freshmen in a rural university in thailand. Transport Policy, 18(5), 719-726.

Meyer, J., \& Beimborn, E. (1998). Usage, impacts, and benefits of innovative transit pass program. Transportation Research Record: Journal of the Transportation Research Board, (1618), 131-138.

Miller, J. H. (2001). Transportation on college and university campuses: A synthesis of transit practice (Transit Cooperative Research Program Synthesis. No. 39). Washington, DC:

Transportation Research Board.

Myers, G., Hagen, D., Russo, T., McMullin, C., Lembrick, A., Silbaugh, B., \& Parker, K. (2006). Benefits of campus transit pass: Study of students' willingness to pay for proposed mandatory transit pass program. Transportation Research Record: Journal of the Transportation Research Board, (1971), 133-139.

Rodríguez, D. A., \& Joo, J. (2004). The relationship between non-motorized mode choice and the local physical environment. Transportation Research Part D: Transport and

Environment, 9(2), 151-173.

Ryerson University. (2018). Referenda. Retrieved from:

https://www.ryerson.ca/governors/elections/Referenda/

Spurr, B. (2018, March 28). U of T students reject discounted TTC pass. Toronto Star. Retrieved from: https://www.thestar.com

StudentMoveTO. (2016). StudentMoveTO 2015 [Dataset]. Requested from: studentmoveto.ca 
Taylor, B. D., \& Norton, A. T. (2009). Paying for transportation: What's a fair price? Journal of Planning Literature, 24(1), 22.

Toronto Transit Commission. (2017, December 11). U-Pass solutions for Toronto postsecondary institutions. Retrieved from: https://www.ttc.ca/

Toronto Transit Commission. (2018, March 20). U-Pass policy framework. Retrieved from: https://www.ttc.ca/

Whalen, K. E., Páez, A., \& Carrasco, J. A. (2013). Mode choice of university students commuting to school and the role of active travel. Journal of Transport Geography, 31, 132-142.

Williams, M. E., \& Petrait, K. L. (1993). U-Pass: A model transportation management program that works. Transportation Research Record, 1404, 74-81.

Zhou, J., 2012. Sustainable commute in a car-dominant city: factors affecting alternative mode choices among university students. Transp. Res. A Policy Pract. 46 (7), 1013-1029.

Zhou, J., 2014. From better understandings to proactive actions: housing location and commuting mode choices among university students. Transp. Policy 33, 166-175.

Zhou, J., 2016. Proactive sustainable university transportation: marginal effects, intrinsic values, and university students' mode choice. Int. J. Sustain. Transp. 10 (9), 815-824.

Zhou, J., Wang, Y., \& Wu, J. (2018). Mode choice of commuter students in a college town: An exploratory study from the united states. Sustainability, 10(9), 3316. 